\title{
Low-latitude geomagnetic signatures during major solar energetic particle events of solar cycle-23
}

\author{
R. Rawat, S. Alex, and G. S. Lakhina \\ Indian Institute of Geomagnetism, New Panvel (W), Navi Mumbai-410218, India \\ Received: 23 August 2006 - Accepted: 26 October 2006 - Published: 21 December 2006
}

\begin{abstract}
The frequency of occurrence of disruptive transient processes in the Sun is enhanced during the high solar activity periods. Solar cycle-23 evidenced major geomagnetic storm events and intense solar energetic particle (SEP) events. The SEP events are the energetic outbursts as a result of acceleration of heliospheric particles by solar flares and coronal mass ejections (CMEs). The present work focuses on the geomagnetic variations at equatorial and low-latitude stations during the four major SEP events of 14 July 2000, 8 November 2000, 24 September 2001 and 4 November 2001. These events have been reported to be of discernible magnitude following intense X-ray flares and halo coronal mass ejections. Low-latitude geomagnetic records evidenced an intense main phase development subsequent to the shock impact on the Earth's magnetosphere. Satellite observations show proton-flux enhancements associated with solar flares for all events. Correlation analysis is also carried out to bring out the correspondence between the polar cap magnetic field perturbations, $A E$ index and the variations of low-latitude magnetic field. The results presented in the current study elucidate the varying storm development processes, and the geomagnetic field response to the plasma and interplanetary magnetic field conditions for the energetic events. An important inference drawn from the current study is the close correspondence between the persistence of a high level of proton flux after the shock in some events and the ensuing intense magnetic storm. Another interesting result is the role of the pre-shock southward IMF $B_{z}$ duration in generating a strong main phase.
\end{abstract}

Keywords. Magnetospheric Physics (Storms and substorms) - Solar Physics, Astrophysics, and Astronomy (Energetic particles; Flares and mass ejections)

Correspondence to: S. Alex

(salex@iigs.iigm.res.in)

\section{Introduction}

The dynamic Sun is characterized by disruptive transient energetic processes, such as solar flares and coronal mass ejections (CME), which are attributed to the temporal and spatial instabilities of the complex solar magnetic field. During solar flares a tremendous amount of energy of the order of $\sim 10^{28}$ ergs is released, whereas in CMEs, higher energy of the order of $\sim 10^{32}$ ergs, accompanied by a huge quantity of mass $\left(\sim 10^{16} \mathrm{~g}\right)$ with a speed ranging from $\sim 300$ to $\sim 2000 \mathrm{~km} / \mathrm{s}$, is released. During active periods, enormous energy emission from the solar interior is sufficient to energize and accelerate the energetic particle population existing in the solar environment. Such outbursts of energetic and accelerated heliospheric particles are called Solar Energetic Particles (SEP) events.

The first observation of SEPs from the Sun was recorded nearly 50 years ago in the form of an abrupt enhancement in the intensity in ground-level ion chambers during the large solar events which occurred in February and March 1942 (Forbush, 1946). Differentiation of the solar energetic particle events as impulsive and gradual SEP events was presented on the basis of their association with solar flares and coronal mass ejections, respectively (Cliver et al., 1983; Cane et al., 1988 and Kahler, 1986, 1992). Cane et al. (1986) observed a difference in the ratio of proton to electron populations for the two classes of SEPs.

The SEP events are characterized by abrupt enhancements in the proton flux in the energy range of $\mathrm{keV}$ to $\mathrm{MeV}$, following the powerful solar emissions. Proton showers associated with solar transient eruptions are accompanied by enormous energy and mass that upon impacting the Earth's magnetosphere, lead to a sudden disturbance in the Earth's magnetic field, known as Geomagnetic storms (Sugiura and Chapman, 1960; Gonzalez and Tsurutani, 1987). A large fraction of the energy associated with the solar ejecta is transferred into the Earth's magnetosphere mainly by the process of magnetic reconnection (Dungey, 1961; Akasofu, 1981; Gonzalez et al., 1994, 1999). Subsequently, this energy is distributed

Published by Copernicus GmbH on behalf of the European Geosciences Union. 
in various regions of the magnetosphere in different quantities. The energetic protons and ions in the energy range between $\sim 20 \mathrm{keV}$ to $\sim 300 \mathrm{keV}$ are trapped in the geomagnetic field and gyrate around the ambient field as a result of the Lorenz force. These ions also experience a westward drift, owing to the presence of gradients and curvatures in the geomagnetic field. The energetic electrons, on the other hand, experience an eastward drift due to gradients and curvatures of the geomagnetic field. This generates a toroidal current in the region from $\sim 2 R_{E}$ to $\sim 7 R_{E}$ and is known as the ring current (Singer, 1957; Baumjohann et al., 1996). This induces a magnetic field opposite to the ambient geomagnetic field, to form a sharp depression in the Earth's magnetic field, called the main phase of the geomagnetic storm. Different geomagnetic storms exhibit diverse evolution profiles that can be attributed to the varying interplanetary conditions. The north-south component of interplanetary magnetic field, " $B_{z}$ ", plays a crucial role in the excitation of the magnetic reconnection process at the magnetopause. During the southward incursion periods of IMF $B_{z}$, the IMF field lines reconnect with the oppositely directed geomagnetic field lines to reinforce the energy transfer (Tsurutani and Gonzalez, 1997; Gonzalez et al., 2001; Feldstein et al., 2003).

The dynamic interaction between solar wind and magnetosphere is widely reflected in high-and low-latitude magnetic variations. The coupling between the solar wind and the high latitudes results in ionospheric convection and subsequent perturbation in polar cap magnetic activity. Several global indices have been defined to indicate the state of the magnetosphere at any given time, namely the $K_{p}$ index, $D_{s t}$ index, $S y m-H$ and $A E$ index. Bartels (1939) proposed a 3-hourly index called the $K_{p}$ index. Mid-latitude magnetometer stations have been chosen for obtaining the $K_{p}$ index, as they are devoid of auroral elecrojet currents. Sugiura (1964) introduced an hourly index and called it the disturbance storm time $\left(D_{s t}\right)$ index, as it is a direct measure of the hourly average of the geomagnetic perturbation. The hourly index is obtained from low-latitude equatorial magnetometer stations to avoid electrojet affects. To describe the geomagnetic fields in mid latitudes with a high time resolution of $1 \mathrm{~min}$, a symmetric index is introduced for the two components of the geomagnetic fields, horizontal $(H)$ and orthogonal $(D)$, and are depicted as $S y m-H$ and $S y m-D$. To obtain magnetic perturbation in the horizontal component $(H)$ at the auroral zone with a 1-min resolution, Davis and Suguira (1966) proposed auroral electrojet $(A E)$ index from a number of stations distributed in the Northern Hemisphere. Another index was introduced by Troshichev et al. $(1979,1988)$ for measuring the disturbances in the polar cap magnetic activity in response to changes in the IMF southward component and solar wind velocity, and was called the polar cap $(P C)$ index. Vennerstroem et al. (1991) and Takalo et al. (1998) investigated the relationship between polar cap magnetic field variations and auroral electrojet activity, and have found a fairly good correlation.
The present study highlights the low-latitude geomagnetic signatures as a consequence of the energetic proton events and associated coronal mass ejections. Sometimes energetic proton events do not show correspondence with geomagnetic signatures. One of the most typical energetic proton events occurred in October 1989 that was characterized by a spike in proton flux but did not have any association with the geomagnetic disturbance (Shea and Smart, 1998). Thus, understanding the geo-effectiveness of the wide varieties of such phenomena is crucial in understanding the near-Earth space environment. The uncertainty for all the four events as obtained from the fit procedure (linear) comes out to be $2-3 \mathrm{~min}$.

\section{Data base examined}

Solar cycle 23 started in year 1996 and peaked in 2000, followed by a second peak in 2001. The solar maximum period is featured by an enhancement in numerous explosive events like large solar flares, coronal mass ejections, solar proton events and consequent geomagnetic storms. The current solar cycle also witnessed intense proton events, as reported by SOHO/CELIAS, out of which four major SEP events are discussed in the present work.

The data set utilized for the current work is taken from various sources. Solar flare and coronal mass ejection (CME) onset information is taken from geosynchronous satellite GOES-8 and LASCO instruments on board the SOHO satellite, respectively. Actual CME onset time considered in the present cases is taken, as suggested by Zhang et al. (2002), with the definition given as the time when CME is at the height of $1.1 R_{S}$ and is calculated by fitting the CME heighttime profile given by the SOHO/LASCO CME catalog, assuming that the CME is moving with a constant speed. Magnetic field and solar wind data are extracted from the SWEPAM and MAG instruments of the upstream spacecraft Advanced Composition Explorer (ACE), located at L1 point (GSE $\sim 240 R_{E}$ ), and the WIND satellite (GSE $\sim 0.1 R_{E}$ to $\sim 85 R_{E}$ ). It may be noted that ACE or SOHO satellites are near the L1 point upstream and hence receive a shock impact $\sim 1 \mathrm{hr}$ prior to the magnetosphere. Proton flux data is taken from the EPAM instrument of ACE and the COSTEP instrument of the SOHO satellite. The interplanetary magnetic field data set contains east-west component $\left(B_{y}\right)$, northsouth component $\left(B_{z}\right)$ of interplanetary magnetic field (IMF) and total IMF $(|B|)$. Solar wind data consists of solar wind speed $\left(V_{s w}\right)$ and proton density $\left(N_{p}\right)$. All the satellite data acquired in this paper has been originally analyzed by respective instrument team members. Low-latitude regions are devoid of auroral and equatorial electrojets effects. In consideration of this point, for the current study, one-minute digital data of the horizontal component $(H)$ from the low-latitude observatories located at Alibag (geographic lat. $18.63^{\circ} \mathrm{N}$, long. $72.87^{\circ} \mathrm{E}$; geomagnetic lat. $10.02^{\circ} \mathrm{N}$, long. $145.97^{\circ}$ ) and Tirunelveli (geographic lat. $8.7^{\circ} \mathrm{N}$, long. $77.8^{\circ} \mathrm{E}$; geomag- 
netic lat. $0.32^{\circ} \mathrm{S}$, long. $149.76^{\circ}$ ) are used. Diurnal departures are computed by subtracting the mean midnight level for the day and have been depicted by $\Delta H_{\mathrm{ABG}}$ and $\Delta H_{\mathrm{TIR}}$ for respective magnetic observatories, which will be used throughout the work presented here. Hourly average values of the storm-time disturbance index $D_{s t}, 1$-min resolution values for the auroral electrojet $(A E)$ index have been acquired from the World Data Center, Kyoto. Magnetic disturbances at the polar cap are measured by polar cap index $(P C)$ and the data is taken from Thule for the northern polar cap.

\section{Case studies}

\subsection{Case 1: 14 July 2000}

\subsubsection{Solar conditions and proton flux}

The most referred to as major proton event of current solar is popularly known as the "Bastille day event". The event originated from an X-ray solar flare of magnitude X5.7 on 14 July 2000 that occurred in the NOAA active region number 9077 , located near the center of the solar disk at $22^{\circ}$ north and $7^{\circ}$ west. Topmost curves in Fig. 1 show the flare characteristics as recorded by GOES- 8 at two wavelengths of 0.5 $4 \AA$ And 1-8 A. The vertical dashed line at 10:03 UT marks the onset of the solar flare on 14 July, with a subsequent peak at 10:24 UT. This solar flare eruption was followed by a proton shower after about $36 \mathrm{~min}$ of the flare maximum, with the enhancement in energetic particle flux observed at 11:00 UT. The bottom panel of Fig. 1 depicts the proton flux at various energy levels including low energy ranges of $47-65 \mathrm{keV}, 112-187 \mathrm{keV}$ and higher energy ranges of $0.31-$ $0.58 \mathrm{MeV}, 0.76-1.22 \mathrm{MeV}, 1.06-1.91 \mathrm{MeV}$ from ACE and 1.99-6.03 MeV from SOHO. Around 11:00 UT, a relatively larger enhancement in the flux of higher energy particles $(0.31-1.91 \mathrm{MeV})$ is seen compared to the increase in the 47$187 \mathrm{keV}$ range particle flux though the background flux levels just before onset of SEP event are much higher for lower energies. A steady profile is observed for the $47-187 \mathrm{keV}$ range particles after the enhancement for nearly a period of $12: 00 \mathrm{~h}$, while in the higher energy range of $0.31-6.03 \mathrm{MeV}$, particle flux continued to increase. Following this pattern a continuously increasing trend can be seen in all energy ranges that persisted until an abrupt enhancement was confronted on the second day of the SEP onset at 14:35 UT. During the period 14:35 UT to 19:10 UT, the $47-187 \mathrm{keV}$ range particles acquired a high flux, of the order of $\sim 10^{5}-10^{7}$ particles $/ \mathrm{cm}^{2} / \mathrm{s} / \mathrm{sr} / \mathrm{MeV}$. A special feature observed in this proton event is the persistence of high proton flux $\left(\sim 3 \times 10^{6}\right.$ particles $\left./ \mathrm{cm}^{2} / \mathrm{s} / \mathrm{sr} / \mathrm{MeV}\right)$ for nearly a period of $4 \mathrm{~h}(15: 00$ 18:55 UT), in all energy channels following the interplanetary shock (Fig. 1).

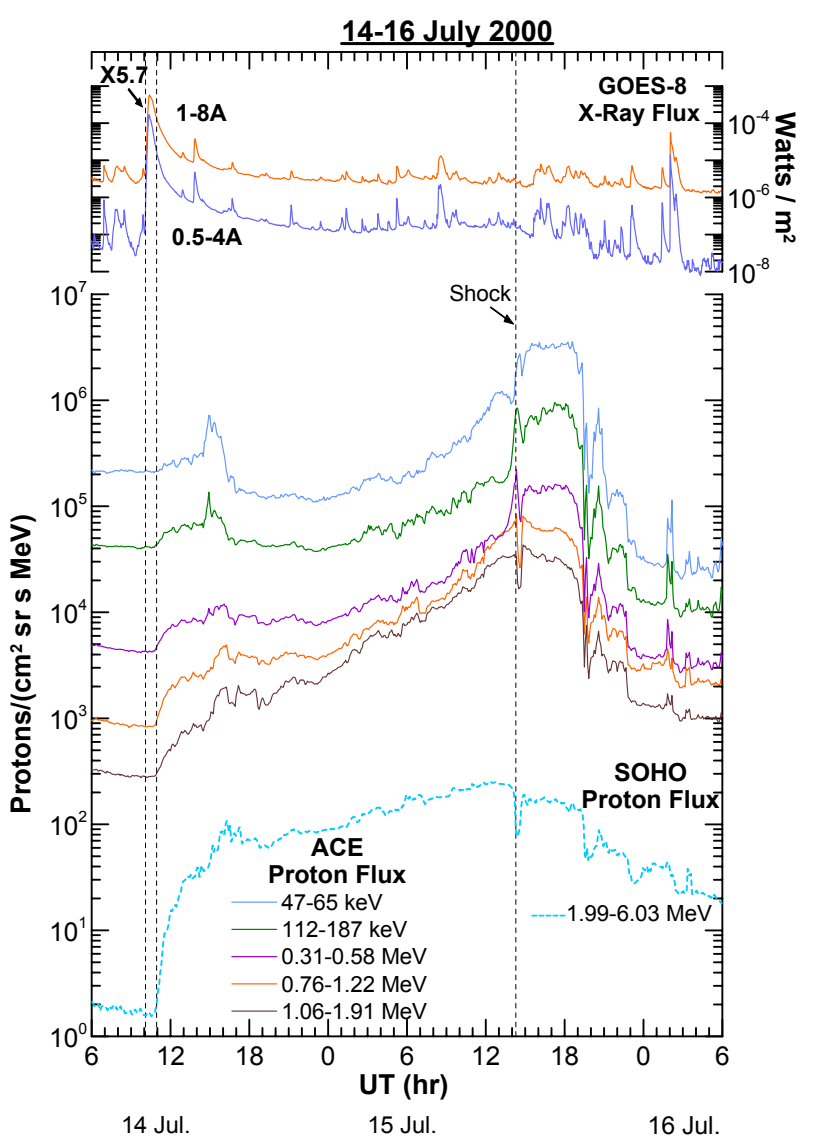

Fig. 1. Upper panel shows $X$-ray flux at two wavelengths $0.5-4$ $\AA$ and 1-8 $\AA$. Proton flux characteristics in various energy levels of $47-65 \mathrm{keV}, 112-187 \mathrm{keV}, 0.31-0.58 \mathrm{MeV}, 0.76-1.22 \mathrm{MeV}$ and 1.06-1.91 MeV (ACE) and 1.99-6.03 MeV (SOHO) for 14-16 July 2000 are shown in the lower panel.

\subsubsection{Interplanetary shock and geomagnetic storm}

In Fig. 2 the interplanetary magnetic field and ground magnetic signatures are reproduced for the intense storm event of 14 July 2000 . The coronal mass ejection traveling with a high speed of $\sim 1674 \mathrm{~km} / \mathrm{s}$, associated with the flare event on 14 July, was recorded by LASCO on board SOHO, on the same day at 10:25 UT. The CME driven interplanetary shock (IPS) was recorded by ACE on 15 July at 14:15 UT after about $27 \mathrm{~h}$ 49 min of CME occurrence. As reported by SOHO (PM), at the time of the shock, $V_{s w}$ and $N_{p}$ increased from $\sim 600 \mathrm{~km} / \mathrm{s}$ to $\sim 800 \mathrm{~km} / \mathrm{s}$ and $\sim 6$ protons $\mathrm{cm}^{-3}$ to $\sim 17$ protons $\mathrm{cm}^{-3}$, respectively. Impingement of the CME shock on the magnetosphere, compressed the magnetopause resulting in a storm sudden commencement (SSC) feature at ground magnetic observations. The SSC was detected at 14:40 UT on 15 July, following the interplanetary shock with a discernible amplitude of $118 \mathrm{nT}$ in the " $H$ " component at the low-latitude Alibag observatory and $103 \mathrm{nT}$ at Tirunelveli, as shown in the lowest panel of Fig. 2. The magnetic storm commenced at 


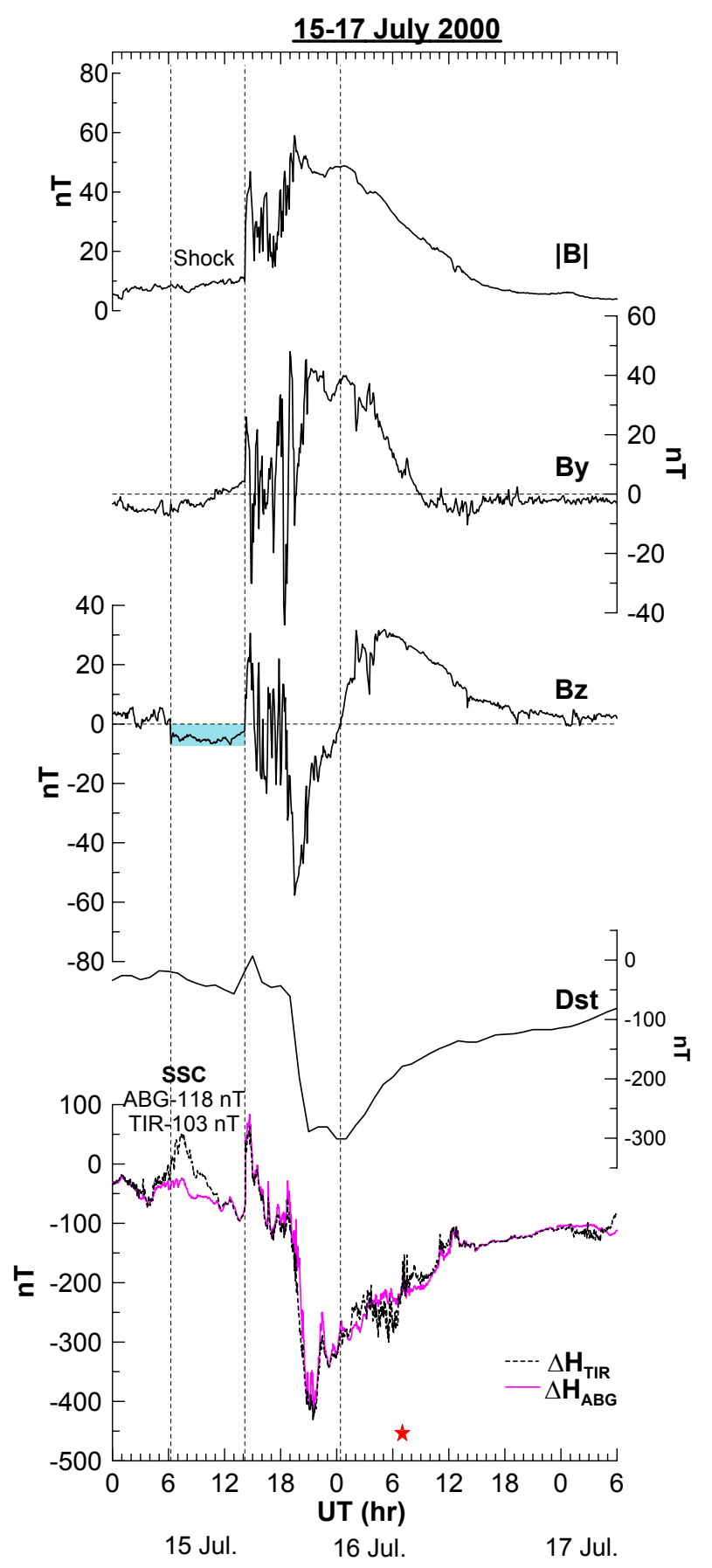

Fig. 2. From top to bottom: IMF $|B|$, IMF $B_{y}$, IMF $B_{z}$, hourly averaged $D_{s t}$ index, 1-mindigital magnetic data $\Delta H_{\mathrm{ABG}}$ and $\Delta H_{\mathrm{TIR}}$ for 15-17 July 2000. Red star (*) depicts local noon.

local nighttime hours for Alibag (ABG). Local noon has been indicated by a red star in Fig. 2. The transit speed of the shock can be assessed by the delay in the arrival of the shock at ACE and that of the SSC at the magnetopause, and for this event the speed has been computed to be $998 \mathrm{~km} / \mathrm{s}$. Following the SSC, from 14:40 to 19:10 UT, an unsteady vari- ation in $\Delta H_{\mathrm{ABG}}$ and $\Delta H_{\mathrm{TIR}}$ persisted for almost $4 \mathrm{~h} 30 \mathrm{~min}$ and correspondingly a consistent fluctuating pattern in IMF $B_{z}$ between the values $-25 \mathrm{nT}$ to $+25 \mathrm{nT}$ was quite evident. During this period IMF $B_{y}$ and the total magnetic field $|B|$ also exhibited some rapid variations, ranging from $-20 \mathrm{nT}$ to $+20 \mathrm{nT}$ for IMF $B_{y}$. The main phase onset is characterized by a sharp depression in $\Delta H_{\mathrm{ABG}}, \Delta H_{\mathrm{TIR}}$ and $D_{s t}$ around 19:10 UT on 15 July, almost with a delay time of $4 \mathrm{~h} 30 \mathrm{~min}$ from the shock impact time. Prior to the storm sudden commencement, IMF $B_{z}$ was oriented southward for $\sim 8 \mathrm{~h}$, with average values $\sim 10 \mathrm{nT}$. At 18:45 UT, IMF $B_{z}$ traversed sharply southward, attaining a peak of $\sim-60 \mathrm{nT}$ at 19:30 UT. Total IMF field $|B|$ steadily acquired high values $\sim 60 \mathrm{nT}$ after the initial oscillating pattern. Low energy particles $(47-187 \mathrm{keV})$ from the proton shower resulted in the enhancement of a westward flowing ring current. The southward orientation of IMF $B_{z}$ lasted for about $5 \mathrm{~h}$ when the IMF turned northward sharply at 00:25 UT on 16 July. During this phase, as inferred from $\Delta H$ for both the low-latitude stations at Alibag (ABG) and Tirunelveli (TIR) (bottom panel of Fig. 2), a sudden decrease in the $\Delta H_{\mathrm{ABG}}, \Delta H_{\mathrm{TIR}}$ field commenced as the $B_{z}$ turned southward, following which the recovery commenced around 22:00 UT.

\subsection{Case 2: 4 November 2001}

\subsubsection{Solar conditions and proton flux}

The proton event of 4 November 2001 is the most intense solar energetic particle event of the current solar cycle, as reported by CELIAS/MTOF. An intense solar flare of magnitude X1, produced by the active region numbered 9684 located at $6^{\circ}$ north $18^{\circ}$ west, occurred at 16:03 UT on 4 November, as recorded by GOES-8 (Fig. 3). After about $45 \mathrm{~min}$ following the flare maximum at 16:20 UT, a proton event occurred at 17:05 UT. Proton fluxes recorded at six energy ranges $(47 \mathrm{keV}$ to $1.91 \mathrm{MeV}$ from $\mathrm{ACE}$ and $1.99 \mathrm{MeV}$ to $6.03 \mathrm{MeV}$ from SOHO) are shown in Fig. 3. The increase in proton flux at all energy ranges at the onset of the proton event at 17:05 UT following the solar flare is followed by a steady increase. Higher energy ranges $(0.31-6.03 \mathrm{MeV})$ exhibit a relatively larger enhancement magnitude $\sim 10^{2}$ particles $/ \mathrm{cm}^{2} / \mathrm{s} / \mathrm{sr} / \mathrm{MeV}$ (lower panel of Fig. 3). The increasing trend in proton flux continued gradually to attain its peak at the shock time of 01:20 UT on 6 November. At this time the flux at all the lower energy ranges experienced an abrupt increase. Similar to the July 2000 proton event, the persisting high proton fluxes $\left(\sim 2 \times 10^{6}\right.$ particles $\left./ \mathrm{cm}^{2} / \mathrm{s} / \mathrm{sr} / \mathrm{MeV}\right)$ in all energy channels are seen after the passage of the interplanetary shock. The striking feature to note is that the fluxes remained at such a large level for a period of $\sim 9 \mathrm{~h}(04: 05-$ 12:55 UT) at the development stage of the intense storm. 


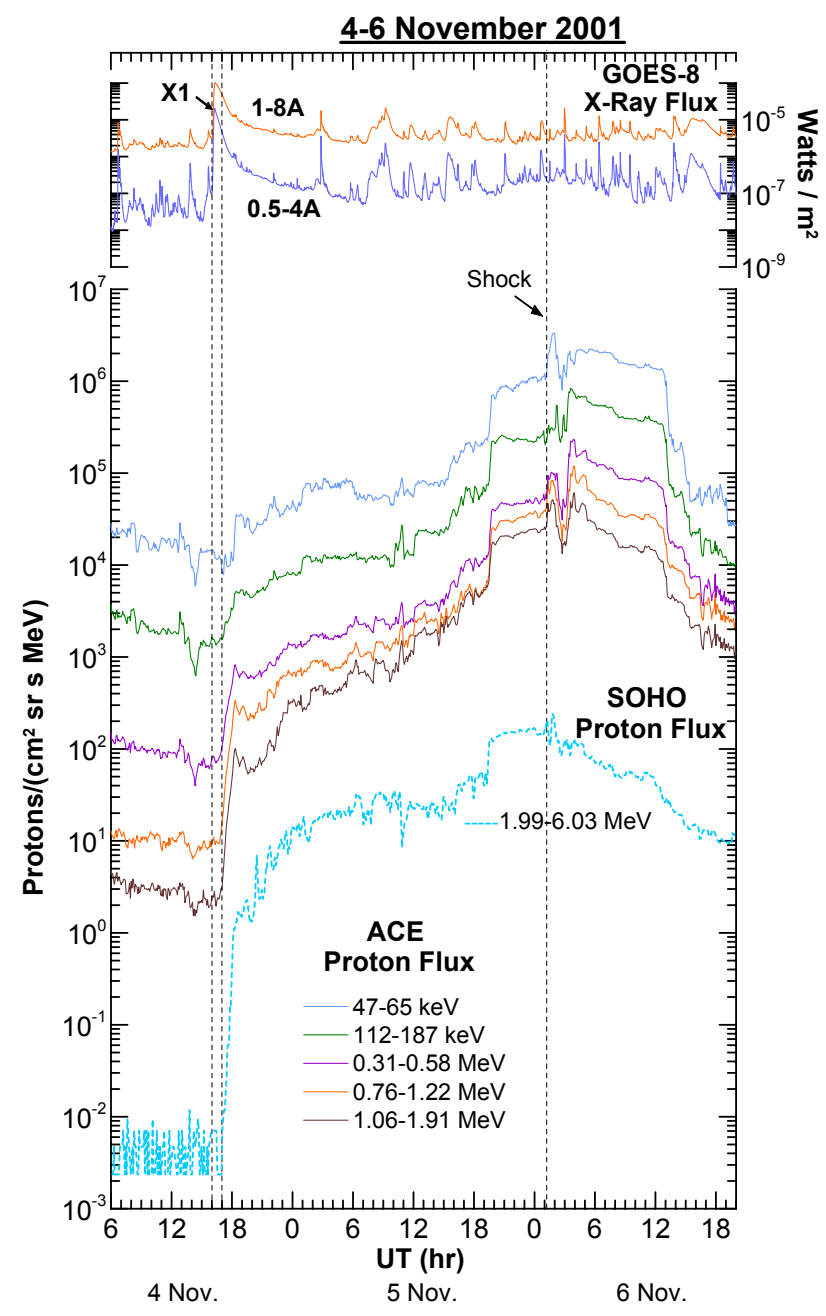

Fig. 3. Upper panel shows X-ray flux at two wavelengths $0.5-4 \AA$ and 1-8 $\AA$. Proton flux characteristics in various energy levels of 47-65 keV, 112-18 keV, 0.31-0.58 MeV, 0.76-1.22 MeV and 1.061.91 MeV (ACE) and 1.99-6.03 MeV (SOHO) for 4-6 November 2001 are shown in the lower panel.

\subsubsection{Interplanetary shock and geomagnetic storm}

On 4 November 2001, a full halo coronal mass ejection occurred at 16:12 UT, associated with X1 solar flare. As recorded by $\mathrm{LASCO} / \mathrm{SOHO}, \mathrm{CME}$ was ejected with a high speed of $\sim 1810 \mathrm{~km} / \mathrm{s}$. The interplanetary parameters and the ground magnetic signatures for the event on 4 November 2001 are reproduced in Fig. 4. The fast CME drove an interplanetary shock that was recorded by ACE after about $\sim 33 \mathrm{~h}$ at 01:20 UT on 6 November 2001, as evidenced by a rapid increase in the solar wind parameters. A significant increase was noted in the solar wind speed $\left(V_{s w}\right)$ from $\sim 475 \mathrm{~km} / \mathrm{s}$ to $\sim 700 \mathrm{~km} / \mathrm{s}$ and the proton density $\left(N_{p}\right)$ from $\sim 4$ protons $\mathrm{cm}^{-3}$ to $\sim 45$ protons $\mathrm{cm}^{-3}$, as reported by $\mathrm{SOHO} / \mathrm{PM}$. About 33 min later, a storm sudden commence-

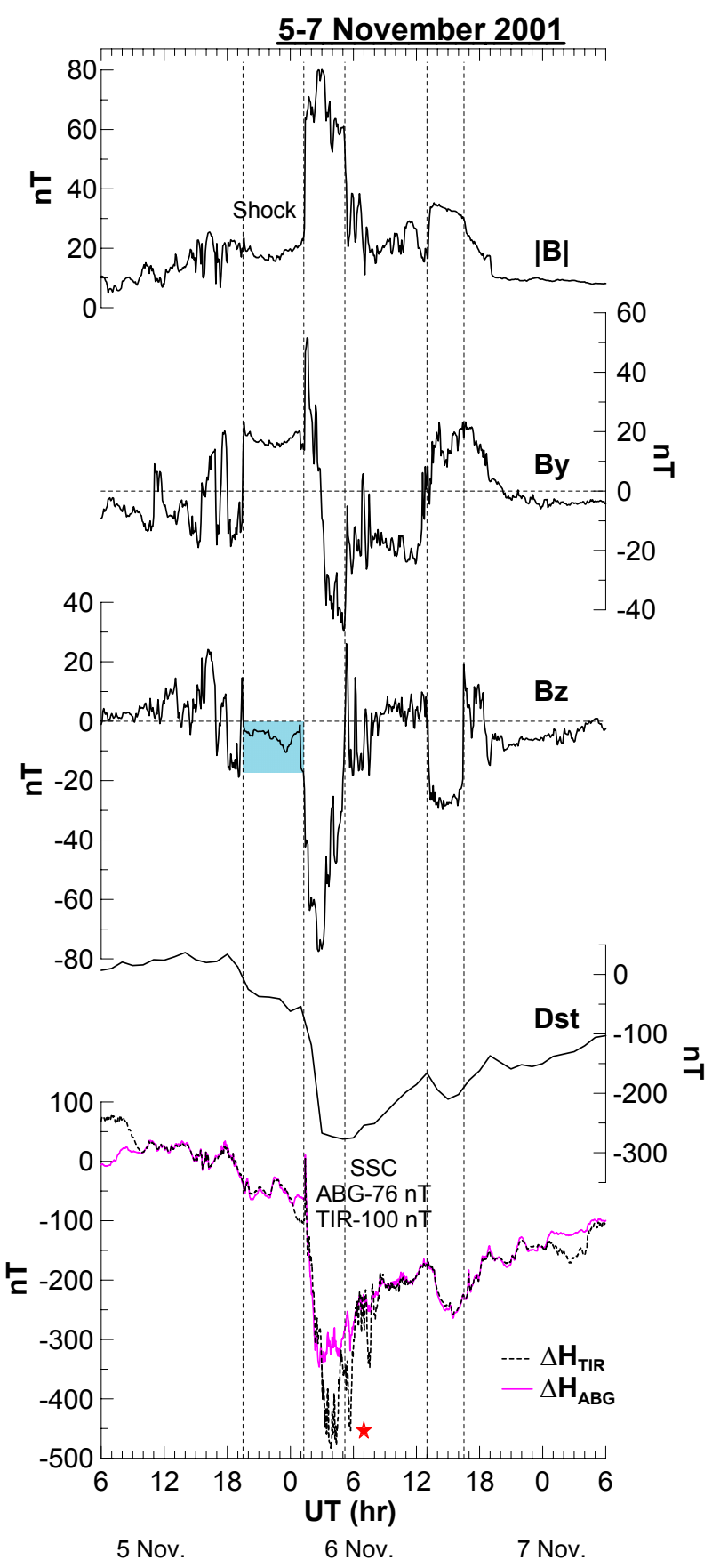

Fig. 4. From top to bottom: IMF $|B|$, IMF $B_{y}$, IMF $B_{z}$, hourly averaged $D_{s t}$ index, 1 -min digital magnetic data $\Delta H_{\mathrm{ABG}}$ and $\Delta H_{\mathrm{TIR}}$ for 5-7 November 2001. Red star (*) depicts local noon.

ment was recorded by the ground observatories on 6 November 2001 at 01:53 UT. The shock transit speed for this case has been assessed to be $756 \mathrm{~km} / \mathrm{s}$. At Alibag, SSC has an amplitude of $76 \mathrm{nT}$, whereas it has an amplitude of $100 \mathrm{nT}$ at Tirunelveli (bottom panel of Fig. 4). The red star in the figure marks the local noon. Referring to the interplanetary 


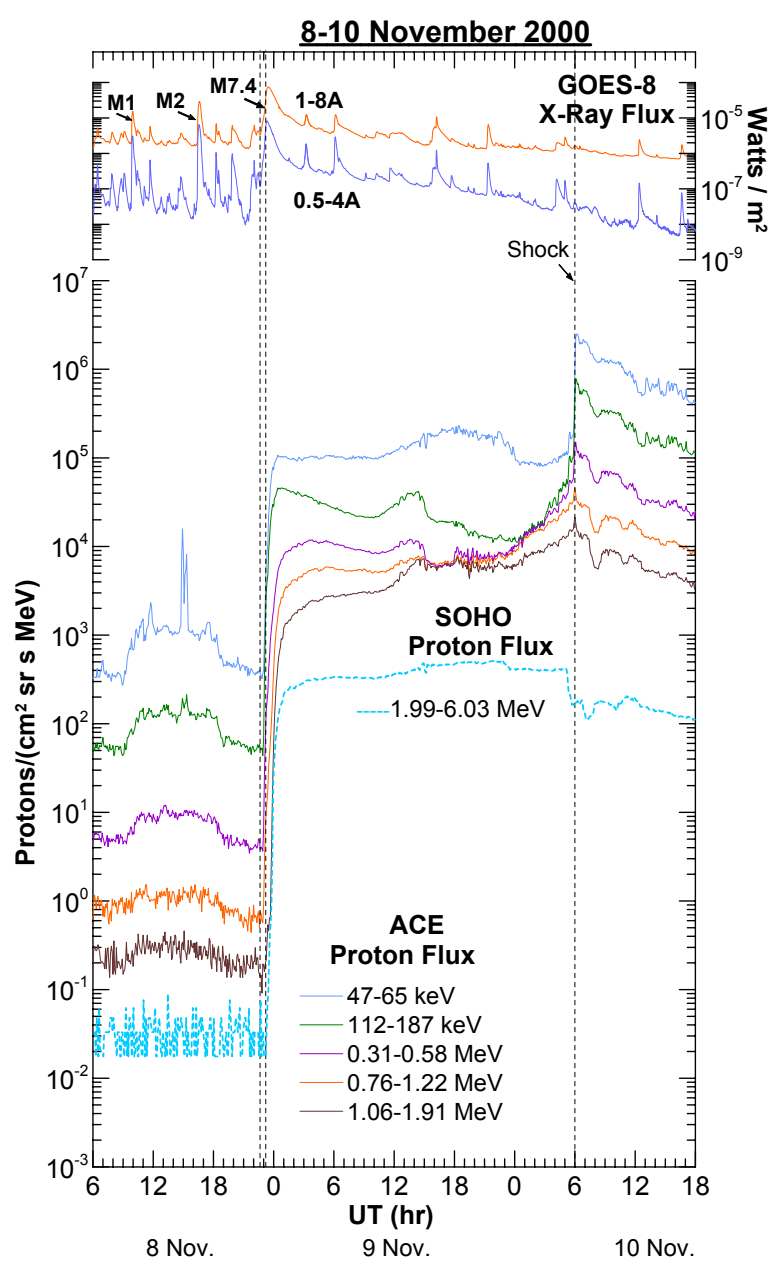

Fig. 5. Upper panel shows $X$-ray flux at two wavelengths $0.5-4$ $\AA$ and 1-8 $\AA$. Proton flux characteristics in various energy levels of $47-65 \mathrm{keV}, 112-187 \mathrm{keV}, 0.31-0.58 \mathrm{MeV}, 0.76-1.22 \mathrm{MeV}$ and 1.06-1.91 MeV (ACE) and 1.99-6.03 MeV (SOHO) for 8-10 November 2000 are shown in the lower panel.

conditions on 5 November, for a period of $\sim 6 \mathrm{~h}$ prior to $\mathrm{SSC}$, the IMF $B_{z}$ was southward with a magnitude of $\sim 10 \mathrm{nT}$ (shaded portion), until a sharp southward traversal occurred at 01:25 UT on 6 November near the shock. This triggered the main phase of the storm as is evident by the sharp decrease in $\Delta H_{\mathrm{ABG}}$ and $\Delta H_{\mathrm{TIR}}$. A significantly large and steady southward IMF $B_{z}$ was observed for almost $4 \mathrm{~h}$, and it is probably responsible for the development of an intense main phase for this event. A peak value of $B_{z} \sim-80 \mathrm{nT}$ was attained at 02:40 UT on the same day, simultaneously IMF $|B|$ maximized to a large value of $\sim 80 \mathrm{nT}$; this led to $D_{s t} \sim-300 \mathrm{nT}$ for this storm. Before the complete recovery of this intense main phase, there was a second phase of southward orientation of $B_{z}$ with a peak value of $\sim-20 \mathrm{nT}$ around 13:10 UT, a concurrent feeble decrease in, $\Delta H_{\mathrm{ABG}}$ and $\Delta H_{\mathrm{TIR}}$ is also evidenced.

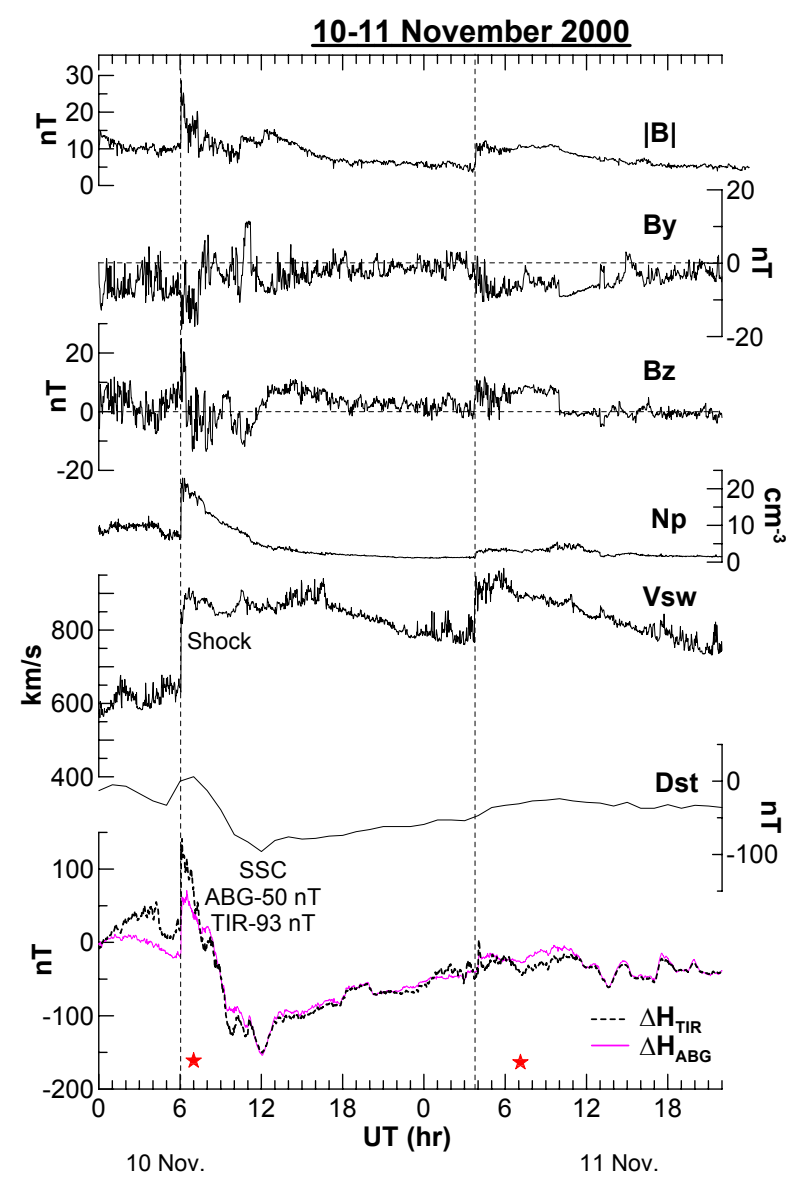

Fig. 6. From top to bottom: IMF $|B|$, IMF $B_{y}$, IMF $B_{z}$, proton density $\left(N_{p}\right)$, solar wind speed $\left(V_{s w}\right)$, hourly averaged $D_{s t}$ index, 1-min digital magnetic data $\Delta H_{\mathrm{ABG}}$ and $\Delta H_{\mathrm{TIR}}$ for $10-11$ November 2000. Red star $(*)$ depicts local noon.

\subsection{Case 3: 8 November 2000}

\subsubsection{Solar conditions and proton flux}

The 8 November 2000 event was characterized by the occurrence of three consecutive M-class solar flares of magnitudes M1.5, M2.9 and M7.4, respectively. A major Mclass M7.4 flare onset was recorded by GOES- 8 at 22:42 UT with a subsequent maximum at 23:28 UT on 8 November, as depicted in the upper panel of Fig. 5. This flare is associated with the active region 9213 located at $10^{\circ}$ north and $22^{\circ}$ west, which produced a major proton event shortly after $23 \mathrm{~min}$ at 23:05 UT on 8 November. A significant enhancement in proton flux in all energy ranges is prominently visible (bottom panel in Fig. 5). High-energy (0.31$6.03 \mathrm{MeV}$ ) particles exhibited a relatively greater magnitude of flux increase of the order of $\sim 10^{4}$ particles $/ \mathrm{cm}^{2} / \mathrm{s} / \mathrm{sr} / \mathrm{MeV}$ in comparison to that at the $47-187 \mathrm{keV}$ level increase of $\sim 10^{2}$ particles $/ \mathrm{cm}^{2} / \mathrm{s} / \mathrm{sr} / \mathrm{MeV}$. A steady pattern is successively observed in all energy ranges which persisted until 


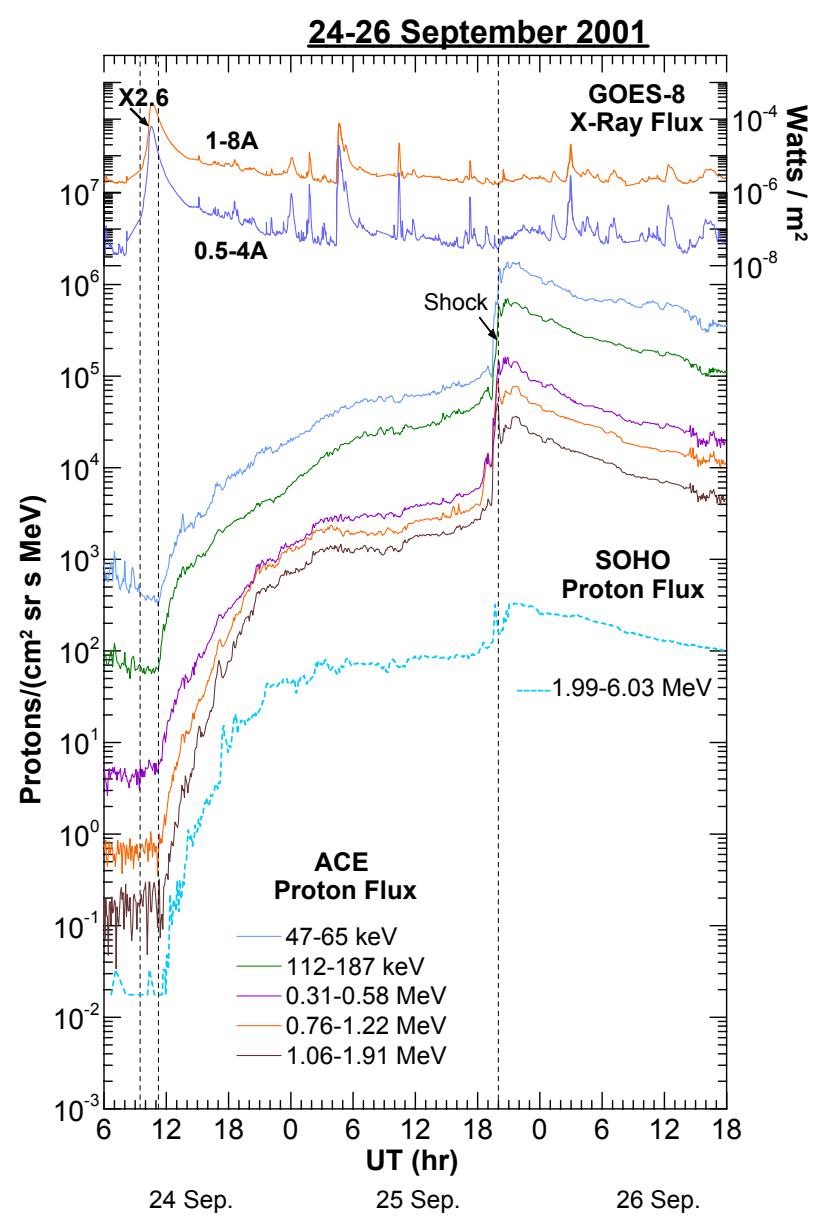

Fig. 7. Upper panel shows X-ray flux at two wavelengths $0.5-4$ $\AA$ and $1-8 \AA$. Proton flux characteristics in various energy levels of $47-65 \mathrm{keV}, 112-187 \mathrm{keV}, 0.31-0.58 \mathrm{MeV}, 0.76-1.22 \mathrm{MeV}$ and 1.06-1.91 MeV (ACE) and 1.99-6.03 MeV (SOHO) for 24-26 September 2001 are shown in lower panel.

another spike was observed at the time of the shock, at 06:00 UT on 10 November. During this enhancement period, particle fluxes in the 47-187 energy of $\mathrm{keV}$ ranges exhibited an increase by an order of magnitude of $\sim 10^{1}$ particles $/ \mathrm{cm}^{2} / \mathrm{s} / \mathrm{sr} / \mathrm{MeV}$ as compared to higher energy levels.

\subsubsection{Interplanetary shock and geomagnetic storm}

A partial halo CME with a high speed of $\sim 1738 \mathrm{~km} / \mathrm{s}$ was reported by LASCO at 22:50 UT. The CME driven interplanetary shock (IPS) was observed at 06:05 UT on 10 November at ACE. Figure 6 illustrates a prominent shock characterized by the abrupt increases in solar wind speed $\left(V_{s w}\right)$ from $\sim 630 \mathrm{~km} / \mathrm{s}$ to about $850 \mathrm{~km} / \mathrm{s}$, proton density $\left(V_{p}\right)$ from $\sim 7$ protons $\mathrm{cm}^{-3}$ to $\sim 20$ protons $\mathrm{cm}^{-3}$ and total interplanetary magnetic field $|B|$ from $\sim 9 \mathrm{nT}$ to $\sim 25 \mathrm{nT}$. After $24 \mathrm{~min}$ of the IPS shock, a storm sudden commencement was observed at 06:29 UT, as recorded at Alibag (ABG), with a

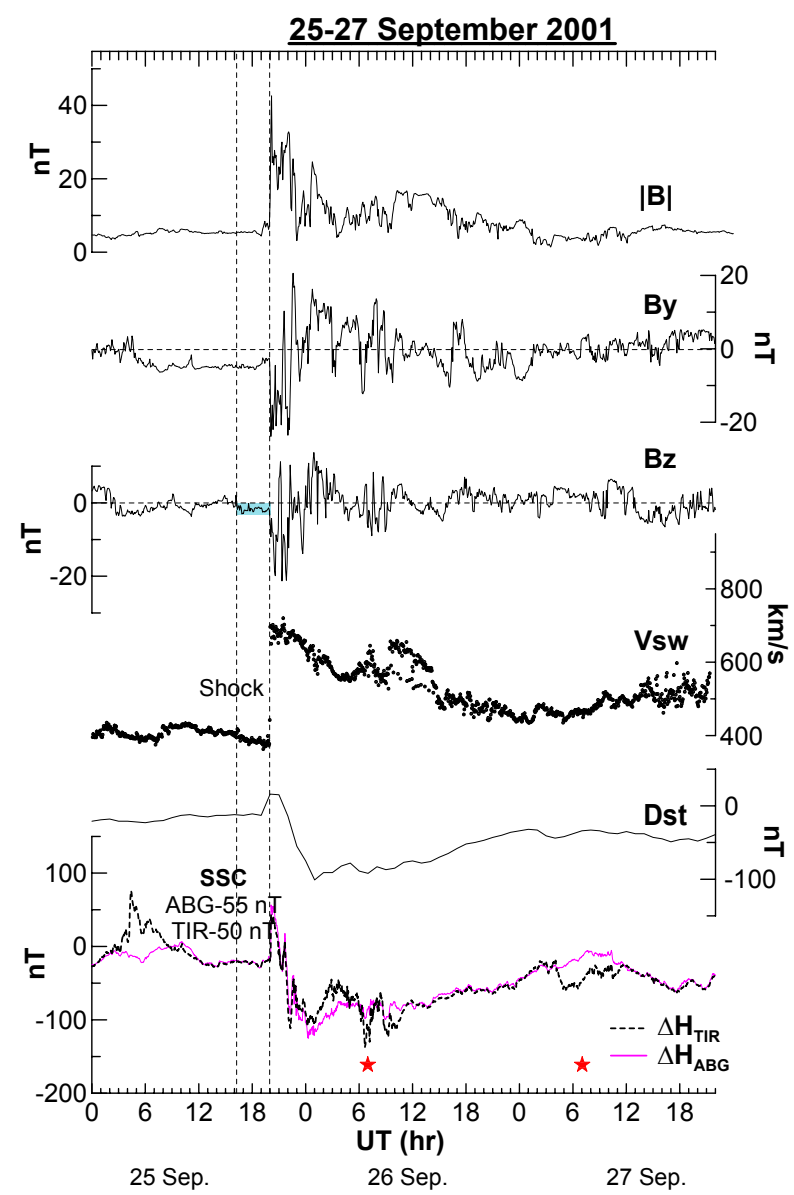

Fig. 8. From top to bottom: IMF $|B|$, IMF $B_{y}$, IMF $B_{z}$, solar wind speed $\left(V_{s w}\right)$, hourly averaged $D_{s t}$ index, 1-min digital magnetic data $\Delta H_{\mathrm{ABG}}$ and $\Delta H_{\mathrm{TIR}}$ for 25-27 September 2001. Red star $\left(^{*}\right)$ depicts local noon.

magnitude of $50 \mathrm{nT}$ (bottom panel of Fig. 6) and of $93 \mathrm{nT}$ at Tirunelveli (TIR). Local noon is shown by a red star in the figure. The interplanetary shock transit speed for this case was found to be $1040 \mathrm{~km} / \mathrm{s}$. The enhanced SSC amplitude at Tirunelveli is the influence of the local noon effect of the equatorial electrojet current. The correspondence in the main phase amplitude at TIR and ABG during local night conditions is perceptibly evident. The north-south component $\left(B_{z}\right)$ of the interplanetary magnetic field was northward at the shock time, but went over to a fluctuating IMF $B_{z}$ with a dominantly southward directed condition after the shock passage. After the SSC at ground, the horizontal component of the geomagnetic field $\triangle H_{A B G}$ started decreasing steadily due to a ring current enhancement by the injection of low energy particles $(47-187 \mathrm{keV})$, giving rise to a main phase with a magnitude of $\sim 176 \mathrm{nT}$. IMF $B_{z}$ exhibited a fluctuating southward directed field, between the values of $\sim+5 \mathrm{nT}$ to $\sim-15 \mathrm{nT}$, until a southward traversal occurred at 10:21 UT on 10 November. A noticeable feature observed in this case 
was the persistence of the solar wind speed $\left(V_{s w}\right)$ between the values of 800 to $850 \mathrm{~km} / \mathrm{s}$, acquired at the shock passage time for $\sim 22 \mathrm{~h}$. Following this steady level another distinct kink with $V_{s w}$, peaking to values of $\sim 950 \mathrm{~km} / \mathrm{s}$, was noticed on 11 November at 04:09 UT, during the recovery phase of this storm. At the same time, some weak signatures of enhancements were also observed in the total interplanetary field, $|B|$. The IMF $B_{z}$, however, was fluctuating from $-3 \mathrm{nT}$ to $+5 \mathrm{nT}$ in that period, thus curbing any significant geomagnetic activity.

\subsection{Case 4: 24 September 2001}

\subsubsection{Solar conditions and proton flux}

The active region 9632 located at $16^{\circ}$ south $23^{\circ}$ east on the solar disk produced an X-class solar flare of magnitude X2.6 on 24 September 2001 at 09:32 UT. The vertical dashed line marks the onset of the flare event (upper panel of Fig. 7). After about 37 min of solar flare maximum which occurred at 10:38 UT on 24 September, a proton event followed at $11: 15$ UT. In the higher energy ranges $(0.31-6.03 \mathrm{MeV})$, higher orders $\left(\sim 10^{4}\right.$ particles $\left./ \mathrm{cm}^{2} / \mathrm{s} / \mathrm{sr} / \mathrm{MeV}\right)$ of flux increase are seen compared to the low energy range $(45-187 \mathrm{keV})$. Steady growth of the proton flux persisted for $\sim 32 \mathrm{~h}$ for all ranges, with another steep hike as observed at 19:25 UT on 25 September, due to the shock, followed by a gradual decay. Magnitude of this enhancement was higher in the 47$187 \mathrm{keV}$ range particle flux.

\subsubsection{Interplanetary shock and geomagnetic storm}

The active Sun of 24 September 2001 produced a major solar flare and a subsequent proton shower, as explained in the section above. Associated with the solar flare on 24 September, a halo CME was recorded by LASCO/SOHO at 10:21 UT on same day, with a high speed of $\sim 2402 \mathrm{~km} / \mathrm{s}$. This Earthdirected CME led to an interplanetary (IP) shock which was observed by ACE at 20:00 UT on 25 September, as depicted in Fig. 8. At the shock passage time, the solar wind speed increased from $\sim 442 \mathrm{~km} / \mathrm{s}$ to $\sim 748 \mathrm{~km} / \mathrm{s}$ and the total IMF $|B|$ jumped from $7 \mathrm{nT}$ to $32 \mathrm{nT}$. After about $27 \mathrm{~min}$, this interplanetary shock, due to the fast halo CME, struck the magnetosphere, resulting in a magnetopause compression that was marked by a storm sudden commencement (SSC) of amplitude $55 \mathrm{nT}$ at Alibag and 50 nT at Tirunelveli at 20:27 UT on 25 September 2001. The storm occurred at local nighttime hours. After the shock (transit speed $920 \mathrm{~km} / \mathrm{s}$ ) impacted at the magnetosphere, the IMF $B_{z}$ was fluctuating from $-25 \mathrm{nT}$ to $+25 \mathrm{nT}$ (Fig. 8). Subsequent to the storm sudden commencement for this storm event, an unsteady and very weak main phase developed ( $\sim 143 \mathrm{nT}$ at Alibag), though the influx of high energy protons into the magnetosphere was plenty.
15 July 2000

Main Phase (1910-2134 UT)
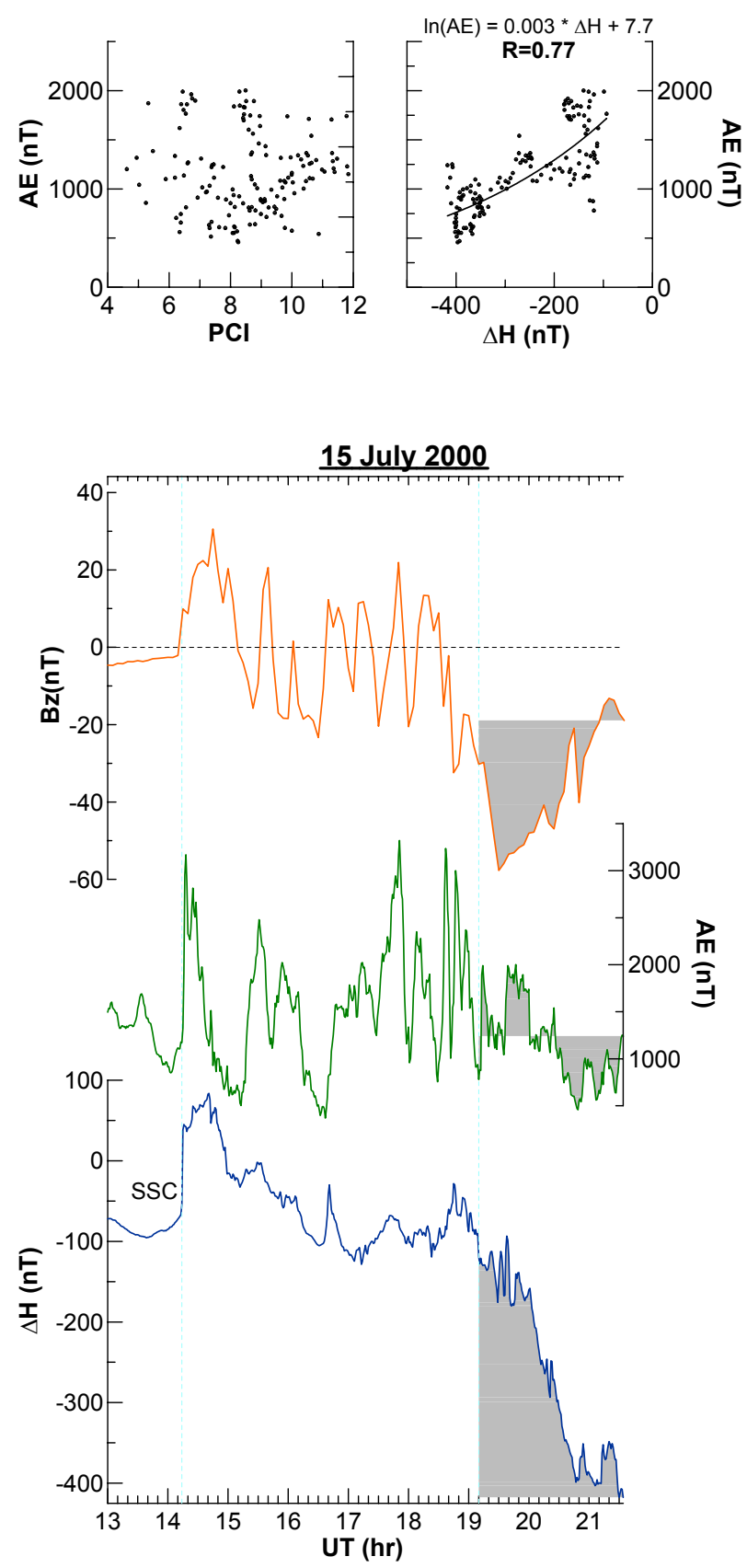

Fig. 9. Upper panel displays the correlations of the polar cap magnetic activity $(P C)$ index and low-latitude geomagnetic field $\triangle H_{A B G}$ with auroral electrojet $(A E)$ index for 15 July 2000 for " $T 1$ " (19:10-21:34 UT) period. Bottom panel shows the variations of auroral electrojet index $(A E)$ and horizontal component of geomagnetic field at Alibag $\left(\triangle H_{\mathrm{ABG}}\right)$ with corresponding interplanetary magnetic field (IMF) north-south component $B_{z}$. 
Table 1. The storm sudden commencement amplitude, main phase duration and main phase magnitude presented in the table are as determined from Alibag observatory records. Order of events is according to decreasing order of main phase magnitude for all cases. All the magnetic field measurements are given in nano Tesla (nT).

\begin{tabular}{cccccc}
\hline Date $^{a}$ & SSC-amplitude $^{b}$ & $T 1^{c}$ & ${\text { MP-magnitude, } D s t_{\min }{ }^{d}}$ & State $^{e}$ & $B_{z} \min ^{f}$ \\
\hline $14 / 07 / 2000$ & $118(15 / 1440$ UT) & 2.2 & $\sim-324,-301$ & Exists & $\sim-60$ \\
$4 / 11 / 2001$ & $76(06 / 0153$ UT) & 1.1 & $\sim-279,-292$ & Exists & $\sim-80$ \\
$8 / 11 / 2000$ & $50(10 / 0629$ UT) & 4.3 & $\sim-176,-96$ & No & $\sim-15$ \\
$24 / 09 / 2001$ & $55(25 / 2027$ UT) & 3.1 & $\sim-143,-102$ & No & $\sim-21$ \\
\hline
\end{tabular}

\footnotetext{
${ }^{a}$ First column refers to the date of solar flare/coronal mass ejection occurrence.

${ }^{\mathrm{b}}$ Storm sudden commencement amplitude (SSC-amp) recorded at Alibag and the date and time of SSC.

${ }^{\mathrm{c}}$ Duration of storm in hours between beginning of sharp depression in magnetic field ( $\left.\Delta H_{\mathrm{ABG}}\right)$ and attainment of minimum value ("T1").

${ }^{\mathrm{d}}$ Main phase magnitude (MP-mag) at Alibag along with minimum $D_{s t}\left(D_{s} t_{\mathrm{min}}\right)$ values attained.

e Persistence of high proton flux post-shock duration.

${ }^{\mathrm{f}}$ Minimum value of $B_{z}\left(B_{z} \mathrm{~min}\right)$.
}

\section{Results}

\subsection{Proton flux characteristics and storm manifestation}

Acceleration of energetic particles at discontinuities in the interplanetary medium, such as the forward and reverse interplanetary shocks, leads to an enhancement of energetic particle flux (Mason et al., 1999; Reames, 1999). In the study of proton events done by Reames (1999), the type of events characterized by a hike near the shock passage time is classified as gradual. The four SEP events discussed in the current study exhibit a similar feature, as mentioned in the above reference, and hence can be sited as gradual solar energetic particle events. The protons fed to the magnetosphere through the SEP events in the energy range of $47-187 \mathrm{keV}$, have been found to contribute substantially to the enhancement of the ring current, leading to the development of the main phase of magnetic storms. Recent work of Smith et al. (2004) has shown a good correspondence between different threshold values of proton flux at low energy ranges and the storm intensity, using the $K_{p}$ index during the periods of significant southward $B_{z}$. All four SEP events discussed here have maximum flux values of the order of $>10^{6}$ particles $/ \mathrm{cm}^{2} / \mathrm{s} / \mathrm{sr} / \mathrm{MeV}$ for $47-187 \mathrm{keV}$ energy ranges. Two intense SEP events of 14 July 2000 and 4 November 2001 are found to exhibit a peculiar pattern of broad maximum at flux magnitude $>10^{6}$ particles $/ \mathrm{cm}^{2} / \mathrm{s} / \mathrm{sr} / \mathrm{MeV}$ for all energy levels just after the shock for $\sim 4 \mathrm{~h}$ and $\sim 9 \mathrm{~h}$, respectively (lower panels of Fig. 1 and Fig. 3). Both of these events were associated with intense magnetic storms. The observation of persisting high proton fluxes at all energies after the shock passage may be one of the factors that can cause intense geomagnetic storms. Case studies presented here have clearly brought out the fact that SEP events with a persistence of high proton flux levels attained through acceleration by shock waves can substantially contribute towards the intensity of the ensuing magnetic storms (July 2000 and November 2001), unlike the SEP events having a rapid decay of high flux values after the shock (November 2000 and September 2001). Nevertheless, the role of interplanetary and solar wind parameters is to be taken into account for the intensity of storms. The association of SEP flux enhancement with coronal mass ejections and their geoeffectiveness has been dealt with in the recent works of Gleisner et al. (2006) and Smith et al. (2004), the latter suggested the existence of overlapping energetic ion enhancements (EIE) during a post shock period when a smaller EIE follows a larger one and a maximum flux attained prevails for a longer duration, thus leading to the development of intense storms.

\subsection{Interplanetary conditions and main phase development}

The interesting study of the correspondence between IMF parameters and the intensity of geomagnetic storms has been done in detail for several decades. Burton et al. (1975) discussed the significant role of southward interplanetary magnetic fields with four geomagnetic storms using interplanetary and solar wind data from Explorer 33 and 35, $D_{s t}$ and $A E$ indices. Later, Gonzalez and Tsurutani (1987) and Gosling et al. (1991) analyzed intense geomagnetic storms $\left(D_{s t}<-100 \mathrm{nT}\right)$ for a period of 500 days and suggested critical values of IMF $B_{z}(\sim-10 \mathrm{nT})$ for a long duration $(>3 \mathrm{~h})$ as an important interplanetary cause for intense geomagnetic storms. This crucial role of the southward interplanetary magnetic field has been re-confirmed by Tsurutani et al. (1997), O'Brien et al. (2000) and Wang et al. (2003). In this work the existence of a threshold for IMF $B_{z}$ was stressed upon for the initiation and strengthening of the ring current. A significant increase in the ring current may not result even though IMF $B_{z}$, below threshold values, persists for a longer 

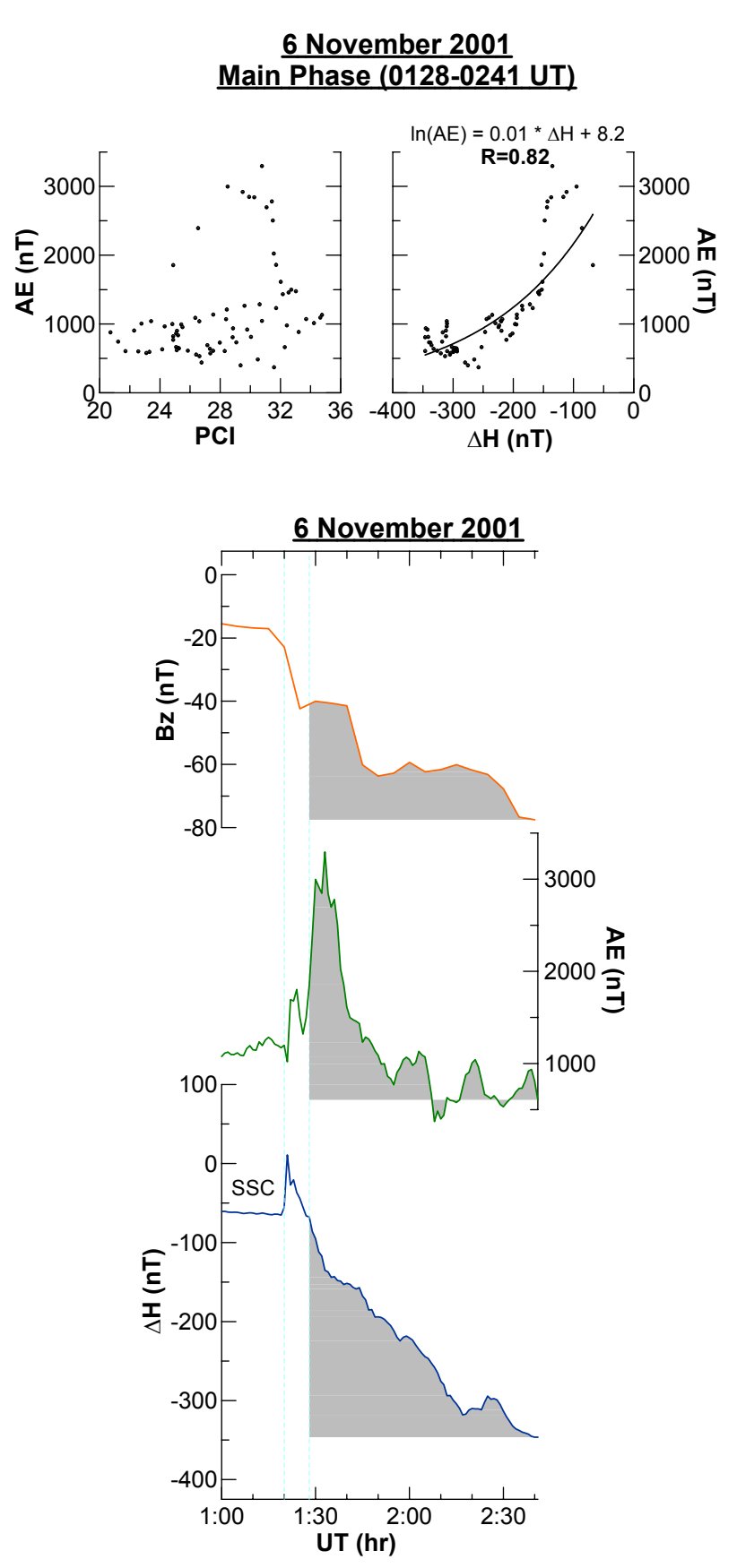

Fig. 10. Upper panel displays the correlations of polar cap magnetic activity $(P C)$ index and low-latitude geomagnetic field $\triangle H_{A B G}$ with auroral electrojet $(A E)$ index for 6 November 2001 for " $T 1$ " (01:28-02:41 UT) period. Bottom panel shows the variations of auroral electrojet index $(A E)$ and $\Delta H_{\mathrm{ABG}}$ with corresponding IMF $B_{z}$.

time. The four storm events under current study have been analyzed to bring out different evolution patterns of the main phase under varying interplanetary conditions. An important point to elucidate in the current study is that prior to the main
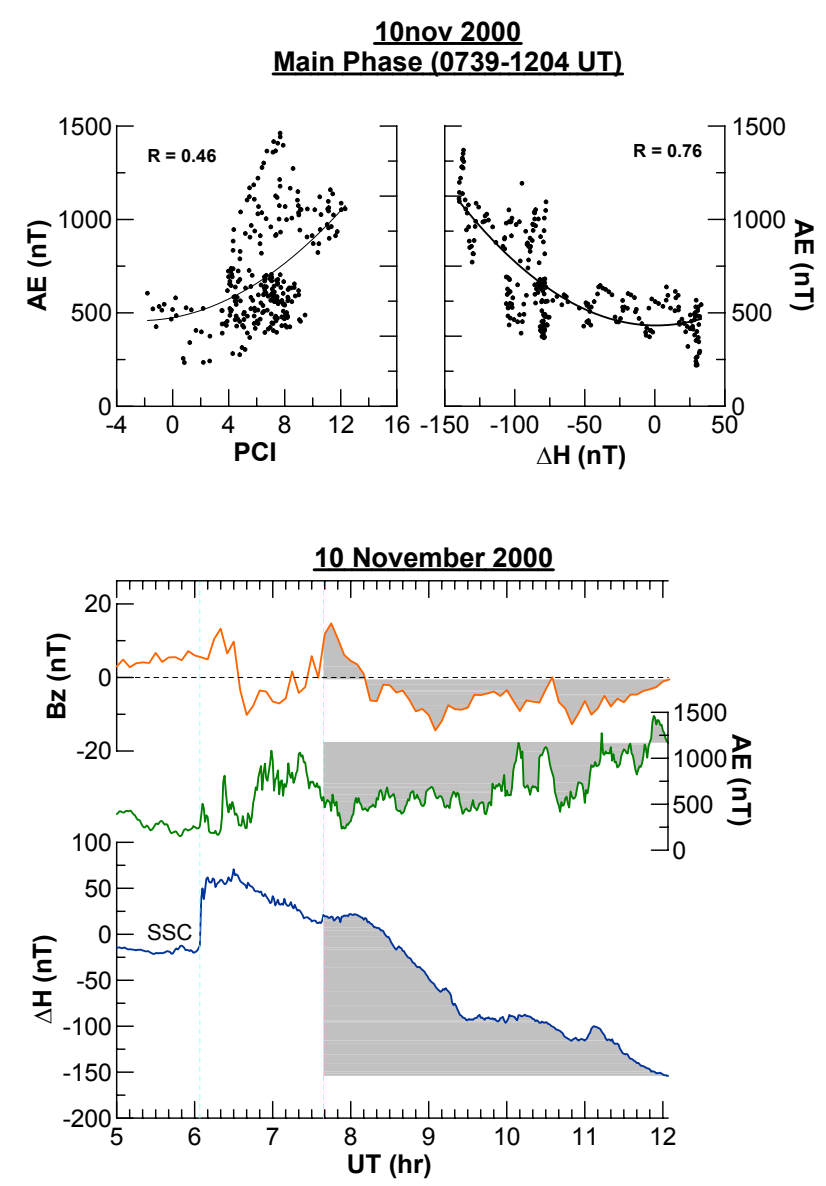

Fig. 11. Upper panel displays the correlations of polar cap magnetic activity $(P C)$ index and low-latitude geomagnetic field $\Delta H_{\mathrm{ABG}}$ with auroral electrojet $(A E)$ index for 10 November 200 for " $T 1$ " (07:39-12:04 UT) period. Bottom panel shows the variations of $A E$ index and $\Delta H_{\mathrm{ABG}}$ with corresponding IMF $B_{z}$.

buildup of the storm, IMF $B_{z}$ had sustained southward orientation for significant durations, with an average magnitude of $\sim 10 \mathrm{nT}$. Particularly for the intense events of 14-15 July 2000 and 4-6 November 2001, IMF $B_{z}$ was southward for $\sim 8 \mathrm{~h}$ and $\sim 6 \mathrm{~h}$, respectively, just before the shock impact on the magnetopause. Subsequently, the storm events of 15-16 July 2000 and 6-7 November 2001 are marked by prolonged and significantly large southward IMF $B_{z}$ after the shock, resulting in the intense main phase development, whereas $8-10$ November 2000 and 24-26 September 2001 are featured by a fluctuating $B_{z}$ and a subdued intense main phase. Hence, the above observations clearly bring out precursory conditions for the buildup of intense geomagnetic storms and can be stated as a smooth southward IMF $B_{z}$ persisting for long duration prior to the shock impact and a continued southward orientation during the subsequent development of the storm are crucial factors for the buildup of intense geomagnetic storms. In the two intense event cases, the main phase 

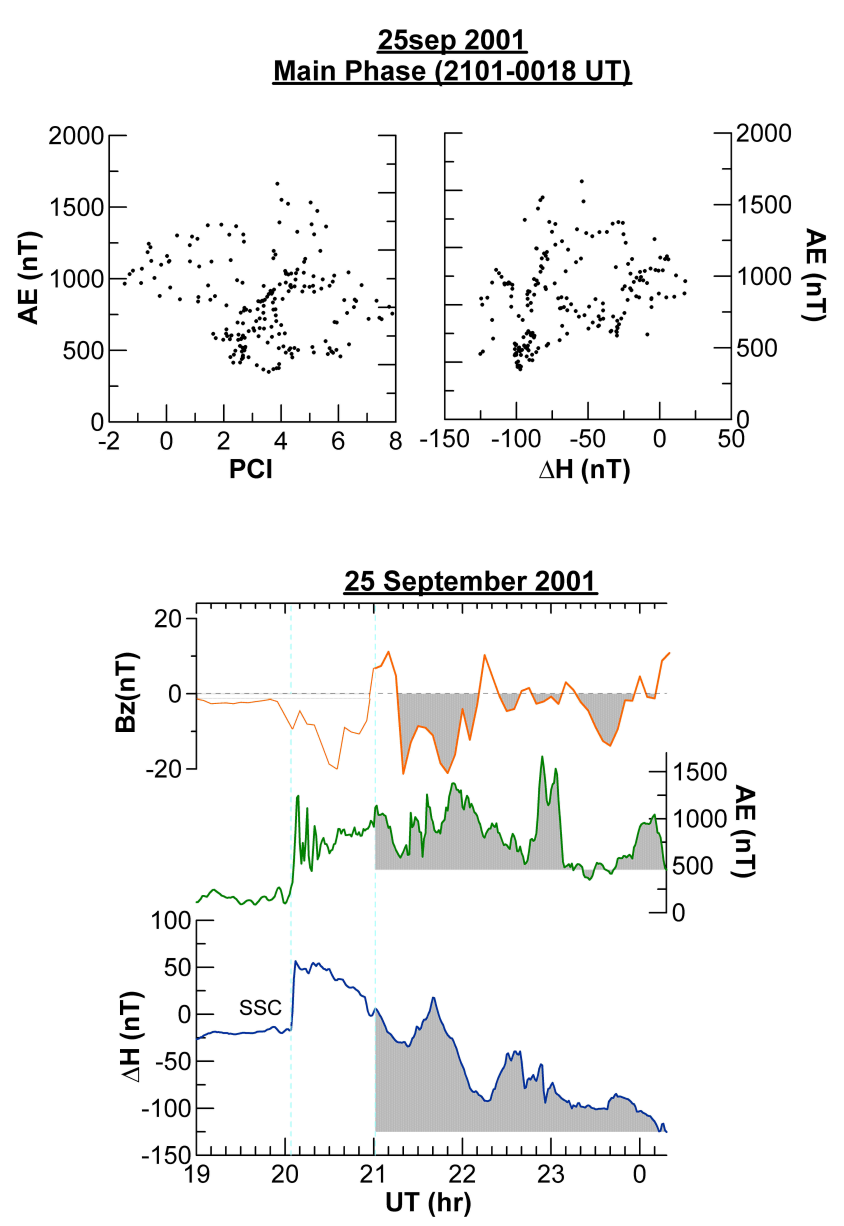

Fig. 12. Upper panel displays the correlations of polar cap magnetic activity $(P C)$ index and low-latitude geomagnetic field $\triangle H_{A B G}$ with auroral electrojet $(A E)$ index for 25 September 2001 for " $T 1$ " (21:01-00:18 UT) period. Bottom panel shows the variations of $A E$ index and $\Delta H_{\mathrm{ABG}}$ with corresponding IMF $B_{z}$.

of the storm developed sharply and was followed by a rapid recovery, whereas in the weak events, the main phase development was a gradual process and decayed after a long time. Intricacies are associated with the manifestation and development of geomagnetic storms, as observed in the ground magnetic records following the unsteady conditions of the interplanetary parameters IMF $B_{y}$ and $B_{z}$. The differentiating characteristics obtained by the current studies of the four SEPs are summarized in Table 1.

\subsection{High-latitude low-latitude coupling process}

The solar wind energy transferred into the magnetosphere, through the dominant mechanism of magnetic reconnection, is redistributed into different regions of the magnetosphere, owing to the varying interactions between energetic charged particles and ambient electric and magnetic fields, leading to the generation of various current systems. A fraction of this
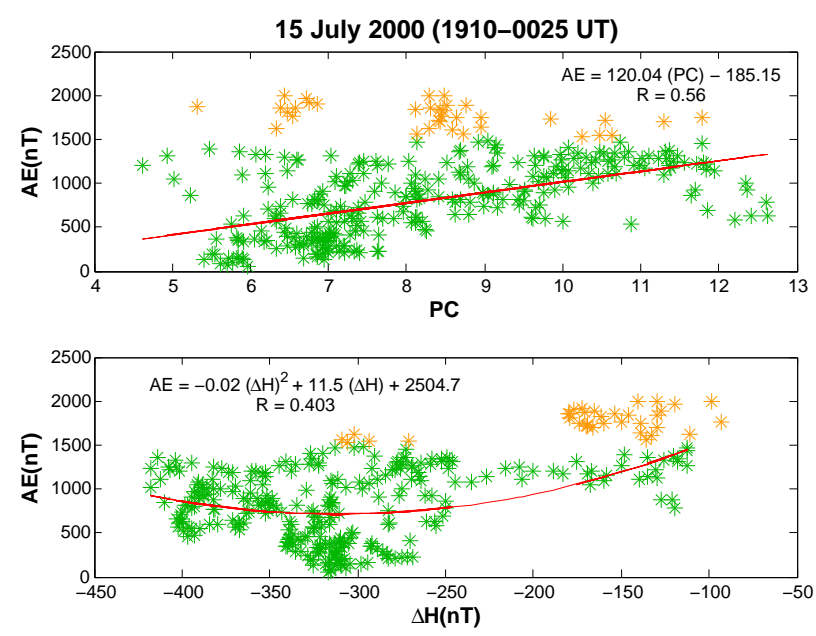

Fig. 13. For " $T 2$ " duration (19:10-00:25 UT) for the 15 July 2000 storm event, correlations between polar cap $(P C)$ index and auroral electrojet $(A E)$ index are depicted in upper panel. Lower panel shows correlations between horizontal component of geomagnetic field at Alibag ( $\triangle H_{\mathrm{ABG}}$ ) and $A E$ index. Green colour symbols represent correlations for $A E$ values lying within $1500 \mathrm{nT}$ and orange colour depicts correlations for $A E$ values more than $1500 \mathrm{nT}$.
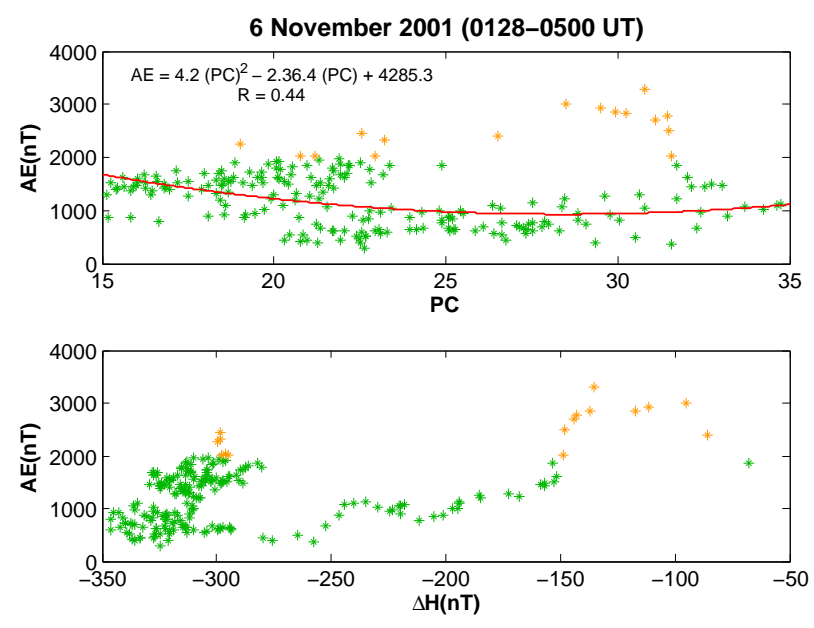

Fig. 14. Illustrates correlations between $P C$ and $A E$ (upper panel) and $\triangle H_{A B G}$ and $A E$ index (lower panel) during " $T 2$ " period (01:28-05:00 UT) of the 6 November 2001 storm event. Green colour represents correlations for $A E$ values lying within $2000 \mathrm{nT}$ and orange colour depicts correlations for $A E$ values more than $2000 \mathrm{nT}$.

energy is transferred to the high latitudes through charged particle precipitation. High-latitude magnetic field variations due to this energy transfer are defined by the auroral electrojet $(A E)$ index.

Criteria to express a well-defined correspondence between the high-latitude indices and the low-latitude geomagnetic field variations are discussed through Fig. 9 to Fig. 16. In 
the case of events presented here, following the shock, the steady and sharp decrease in the $H$ variation at Alibag commenced in phase with the intense southward turning of IMF $B_{z}$. Therefore, in current correlation analysis, the beginning time for the correlation analysis is taken from the point where the actual depression in the ground magnetic data $(H)$ was recorded but the end times have been chosen under two categories of time range. Time duration, defined as "T1", corresponds to the storm period from the onset of the actual depression in $\triangle H_{A B G}$ to the time where the minimum value of $\triangle H_{A B G}$ is attained. For respective storm events, the values given in brackets specify "T1", for example, 15 July 2000 (19:10-21:34 UT), 6 November 2001 (01:28-02:41 UT), 10 November 2000 (07:39-12:04 UT) and 25 September 2001 (21:01-00:18 UT). Figure 9 and Fig. 10 represent correlations obtained for the period of the main phase "T1" (shown by shaded portion) for the two intense events of 15 July 2000 (19:10-21:34 UT) and 6 November 2001 (01:28-02:41 UT), between low-latitude magnetic variations, polar cap magnetic fields and auroral electrojets. Distinct scattered distributions are clearly seen between $A E$ and $P C$ indices in the both cases, as seen in the left sections of the upper panels (Fig. 9 and Fig. 10). $A E$ and $\Delta H_{A B G}$ follow good exponential fits, describing an exponential decay of auroral activity with the buildup of the ring current with correlation coefficients 0.77 and 0.82 , respectively (right sections of the upper panels in Fig. 9 and Fig. 10). On the other hand, for the two weak storm events of 10 November 2000 and 25 September 2001, a clear scattering between the $A E$ and $P C$ indices and $\triangle H_{A B G}$ is observed for the "T1" durations, 07:39-12:04 UT and 21:01-00:18 UT respectively (top panels of Fig. 11 and Fig. 12). To summarize, a predominantly large correlation coefficient between the distinctly strong depression in the $\triangle H_{A B G}$ and the auroral activity, as seen in the case of two intense storm events, clearly explains the influence of the interplanetary conditions and persisting high flux on the lowlatitude magnetic field variations. However, association between auroral activity and polar cap field variations does not seem to follow any defined pattern for the time interval considered.

The present work has brought out two classic examples of intense main phase storm events distinguished by varying interplanetary and the low-latitude ground magnetic fields. The event of 15 July 2000 is characterized by a $4 \mathrm{~h} 30 \mathrm{~min}$ long initial phase but with rapid fluctuations in IMF $B_{z}$ and lowlatitude magnetic field at Alibag $\left(\triangle H_{A B G}\right)$ and Tirunelveli $\left(\triangle H_{T I R}\right)$. Correspondingly, during the same period the $A E$ index peaked to large values $\sim 3400 \mathrm{nT}$, though in an unsteady manner, and this can be attributed to the oscillations in IMF $B_{z}$, as clearly visible from the three lower panels of Fig. 9. This result obtained for the 15 July 2000 event is in good conformity with a similar study carried out by Russell et al. (2000) for the case of 24 September 1998. Their work pointed out that there is an enhancement in activity of auroral electrojets during the oscillating IMF $B_{z}$ periods. In the
July 2000 event, the auroral electrojet index started decreasing just with the onset of the sharp main phase (19:25 UT, 15 July) when the IMF $B_{z}$ became southward, as seen in Fig. 9 (lower panel). A reasonable explanation for this observation could be that before the buildup of the ring current, the energy transferred into the magnetosphere is utilized exclusively to maintain the auroral substorms and later the ring current energy is also supplied from the same reservoir, leading to a decrease towards auroral electrojets. A noticeable feature seen for the 6 November 2001 storm is a sudden enhancement in the $A E$ index to values $\sim 3300 \mathrm{nT}$ just at the time of the actual main phase onset, which corresponds to an increased southward magnitude of IMF $B_{z}$ (bottom panel in Fig. 10). The weak development of the main phase during the 10 November 2000 and 25 September 2001 events can be attributed to less energy input into the magnetosphere, as IMF $B_{z}$ was only $-10 \mathrm{nT}$ to $+10 \mathrm{nT}$ and was fluctuating, and this produced an increase in the auroral index during the main phase (Fig. 11 and Fig. 12). This can also be explained in terms of energy input and redistribution into the magnetosphere. In both the cases, the larger fraction of energy fed into the magnetosphere was extracted for auroral activity; hence, a lesser portion was available for the ring current buildup, leading to only weak growth of the main phase. It is, however, not possible to estimate what fraction of input energy would go into auroral activity or into the ring current for any given interplanetary condition.

Investigations dealing with the association of the polar cap magnetic activity index $(P C)$ with the auroral electrojet index $(A E)$ were carried out by Vassiliadis et al. (1996) and Troshichev et al. (2002). Their studies have shown the existence of a good correlation between the $P C$ index and the auroral electrojet $(A E)$ indices, hence it was concluded that the relationship can be used for the specification of auroral geomagnetic activity and also for nowcasting the intensity of the auroral substorms. In order to examine the correspondence between the polar cap magnetic activity, auroral electrojet activity and ground signatures in a more defined manner, a different time interval "T2" is considered, which can be defined as the duration between the time at which the onset of the depression of $\triangle H_{A B G}$ was observed to the time of the northward traversal of IMF $B_{z}$. For the respective storms the "T2" durations are specified further: 15 July 2000 (19:10-00:25 UT), 6 November 2001 (01:28-05:00 UT), 10 November 2000 (07:39-12:05 UT) and 25 September 2001 (21:01-22:10 UT). In our results, for the July 2000 event, there exists a linear pattern $(\mathrm{R}=0.56)$ for the scatter between $P C$ and $A E$ (Fig. 13), for $A E$ values less than $\sim 1500 \mathrm{nT}$ (green symbols), above this range a clear scattering is seen (orange symbols in upper panel of Fig. 13). Similarly, for the intense events of November 2001 (Fig. 14), there exists a trend in the second order fit between $P C$ and $A E$, until $A E$ reached values of $\sim 2000 \mathrm{nT}$, whereas a scattered distribution for higher values of $A E$ is seen, as depicted by green and orange symbols in the upper panel of Fig. 14, respectively. 
The saturation feature for $A E$ values observed in the July 2000 and November 2001 events is similar to the results obtained by Lu et al. (1998), where the cross polar cap potential drop tends to saturate after $A E$ exceeds about $1000 \mathrm{nT}$. On the other hand, for the weak storm events of 10 November 2000 and 25 September 2001, comparatively low auroral activity occurred during the "T2" period, with $A E$ reaching only $\sim 1300 \mathrm{nT}$ and $\sim 1700 \mathrm{nT}$, respectively (upper panels of Fig. 15 and Fig. 16). For intense storm events the correspondence between the $A E$ and $P C$ indices holds good until a threshold level.

The lower panels of Fig. 13 and Fig. 14 display the correlation between the geomagnetic field variations at Alibag $\left(\triangle H_{A B G}\right)$ and the auroral electrojet index $(A E)$. A second order fit trend with $\mathrm{R}=0.403$, between $\triangle H_{A B G}$ and $A E$, seems to exist for storm event of 15 July 2000 (bottom panel of Fig. 13). For the 6 November 2001 event, there is a sudden increase in $A E$ until $\sim 3300 \mathrm{nT}$ at the time of the main phase onset, as seen in the bottom panel of Fig. 14. Even for the slightly different main phase period considered for all events, it is found that in the storm event cases of 15 July 2000 and 6 November 2001, a common feature of the reduction of the auroral electrojet index with the advancement of main phase of the storms stands out clearly (lower panels in Fig. 13 and Fig. 14). On the other hand, the two weak events of 10 November 2000 and 25 September 2001 are found to have increased in auroral activity with the progress of the storm main phase ("T2"). Particularly in the case of 10 November 2000, a significant correlation $(\mathrm{R}=0.77)$ between $\triangle H_{A B G}$ and $A E$ supports the above mentioned point.

\section{Discussion and conclusions}

Varying ranges of the storm intensity associated with the background proton events and interplanetary conditions are summarized as follows:

1) Investigations by Smith et al. (2004) and Gleisner and Watermann (2006) emphasized the discriminating contribution of SEP flux characteristics to assess the geoeffectiveness of CMEs in producing strong magnetic storms. Our study shows that the SEP events with high flux levels or a "plateau" after the shock passage (i.e. 15 July 2000 and 6 November 2001) produce much more intense storms than the events where the SEP flux levels decrease after the shock passage, i.e. 10 November 2000 and 25 September 2001, even when the maximum SEP flux achieved is similar. A probable explanation for this can be that during plateau SEP events, the magnetotail become pre-populated with large fluxes of energetic particles due to the dayside magnetic reconnection. Subsequent injecting of these energetic particles to the inner magnetosphere produces an intense ring current, leading to high $\left|D_{s t}\right|$ values.

2) For both 15 July 2000 and 6 November 2001 SEP events
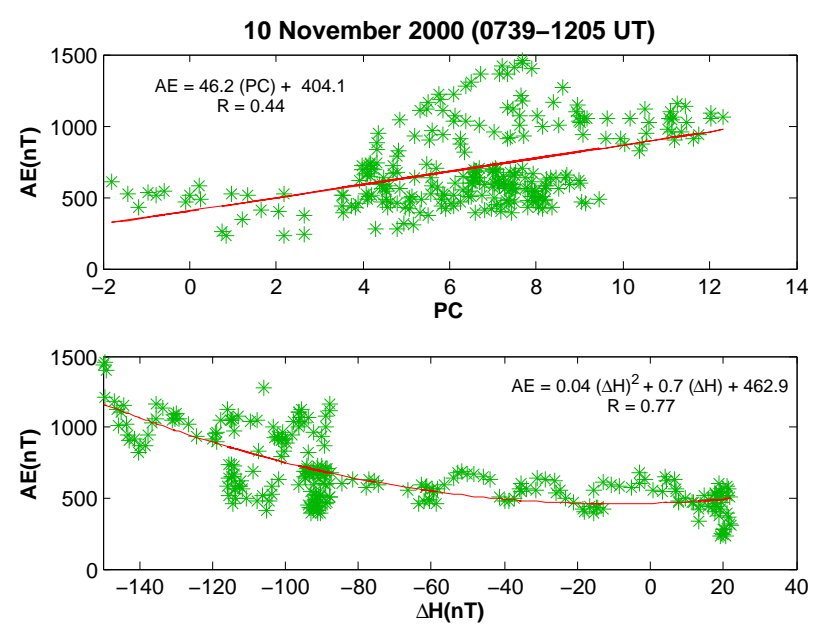

Fig. 15. Correlations between $P C$ and $A E$ (upper panel) and $\triangle H_{\mathrm{ABG}}$ and $A E$ index (lower panel) during " $T 2$ " period (07:3912:05 UT) of the 10 November 2000 storm event.
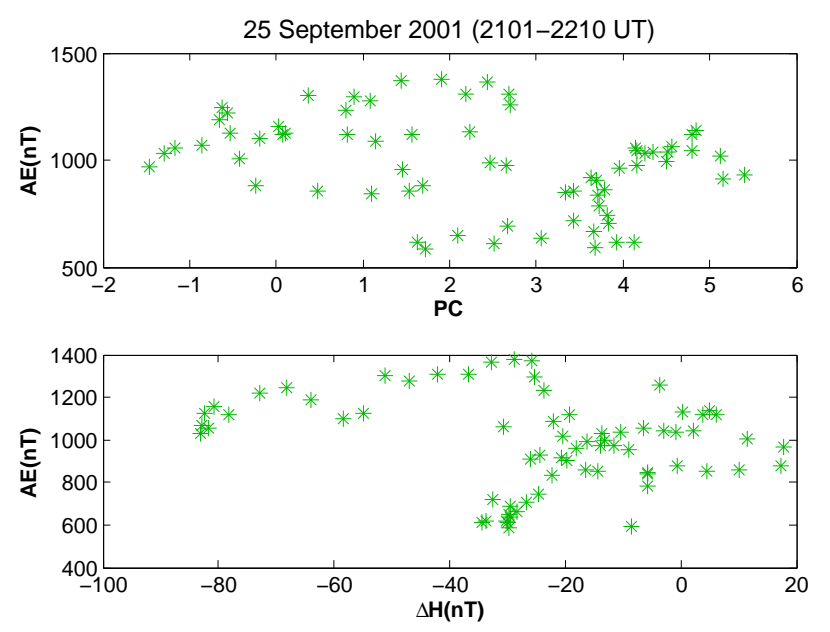

Fig. 16. Correlations between $P C$ and $A E$ (upper panel) and $\triangle H_{\mathrm{ABG}}$ and $A E$ index (lower panel) during " $T 2$ " period (21:0122:10 UT) of the 25 September 2001 storm event.

with high flux levels, during the main phase of the ensuing geomagnetic storms, the $A E$ index decreased as the main phase developed. The converse was true for the SEP events where the flux level decreased after the shock (10 November 2000 and 25 September 2001).

$3)$ For the two intense SEP events, a definite correlation pattern between the $A E$ index and $P C$ index was found when the $A E$ index was below some threshold value. Above this threshold value, there is a large scatter and the correlation is poor.

4) A summary plot showing the effect of the duration of the southward IMF $B_{z}$ just before the shock impingement on the development of magnetic storms for all four events is given in Fig. 17. To delineate the storm intensities corresponding 


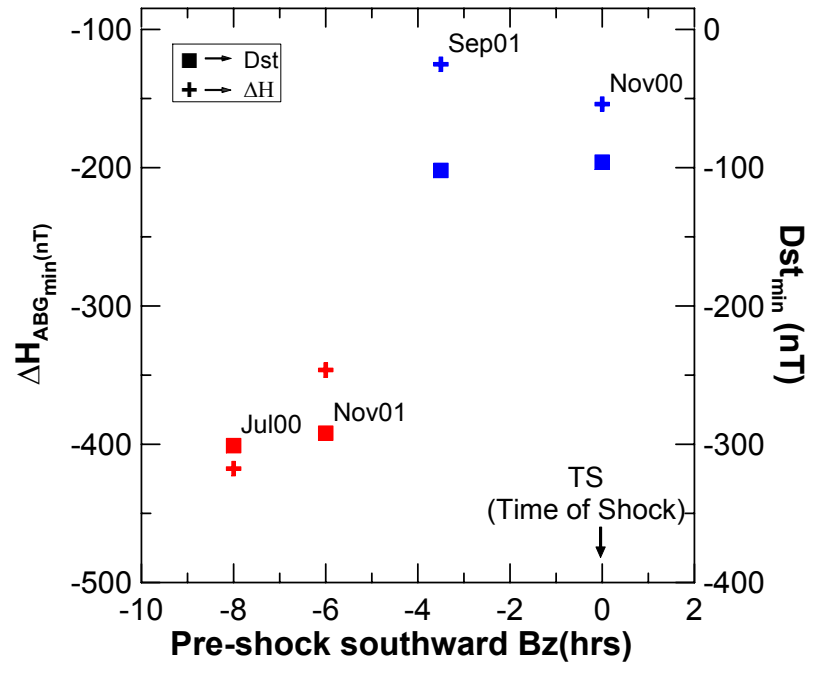

Fig. 17. Illustrates correspondence of $\Delta H_{\mathrm{ABG}}$ minimum (filled "+" signs) with a duration of southward $B_{z}$ before shock and $D_{s t}$ min (filled square symbols) for four SEP events. "TS" indicates the shock time. The pre-shock hours with southward IMF $B_{z}$ are marked with respect to the shock time. Red colour symbols depict two intense main phase events of July 2000 and November 2001. For intensity of these storms, see the degree of depression in the Alibag magnetic field and high level of auroral activity. Weak main phase events of November 2000 and September 2001 have been shown by blue symbols. These two cases can be identified by lower values of $\Delta H_{\mathrm{ABG}}$ minimum and $A E$ values.

to the duration of southward $B_{z}$ prior to storm onset, Alibag magnetic variations $\left(\triangle H_{A B G}\right)$, as well as the $D_{s t}$ index, are depicted against the duration of pre-shock negative $B_{z}$ for the four events examined. Red symbols indicated in the figure are for the intense storms of 15 July 2000 and 6 November 2001. Extended durations ( $\sim 8 \mathrm{~h}$ and $\sim 6 \mathrm{~h}$, respectively) of pre-shock $B_{z}$ is evident for the two storms in contrast to the negligibly low pre-shock conditions of $B_{z}$ for the other two events. "TS" against " 0 " hr time is the shock time, with respect to which the negative $B_{z}$ is considered. This result could well be used to explain the precursory signature for the intense storm phenomena.

The conclusions from the present study are drawn from a limited number of events only. Examination of a greater number of events will certainly extend support to the validity of our conclusions concretely.

Acknowledgements. The authors are thankful to CELIAS/MTOF experiment on the Solar Heliospheric Observatory (SOHO) spacecraft for providing the solar wind and the interplanetary data. SOHO is a joint European Space Agency (ESA) and United States National Aeronautics and Space Administration (NASA) mission. We thank ACE SWEPAM instrument team and the ACE Science Center for providing the interplanetary data. We are also thankful to WIND instrument team for interplanetary data. We acknowledge WDC, Kyoto for providing the $A E$ and $D_{s t}$ indices. We also thank NASA website from where coronal mass ejection informa- tion was extracted. This CME catalog is generated and maintained by NASA and The Catholic University of America in cooperation with the Naval Research Laboratory. SOHO is a project of international cooperation between ESA and NASA. G. S. Lakhina would like to thank H. Matsumoto and Y. Omura for their kind hospitality at Research Institute for Sustainable Humanosphere, where a part of this work was done. G. S. Lakhina thanks the Council of Scientific and Industrial Research, Government of India, for providing support under Emeritus scientist scheme.

Topical Editor B. Forsyth thanks C. Cid and another referee for their help in evaluating this paper.

\section{References}

Akasofu, S.-I.: Energy coupling between the solar wind and the magnetosphere, Space Sci. Rev., 28, 121-190, 1981.

Bartels, J., Heck, N. H., and Johnston, H. F.: The three-hourrange index measuring geomagnetic activity, J. Geophys. Res., 44, 411-454, 1939.

Baumjohann, W., Kamide, Y., and Nakamura, R.: Substorms, storms and the near-Earth tail, J. Geomagn. Geoelect., 48, 177$185,1996$.

Burton, R. K., McPherron, R. L., and Russell, C. T.: An empirical relationship between interplanetary conditions and $D_{s t}$, J. Geophys. Res., 80, 4204-4214, 1975.

Cane, H. V., McGuire, R. E., and von Rosenvinge, T. T.: Two classes of solar energetic particle events associated with impulsive and long duration soft x-ray flares, Astrophys. J., 301, 448459, 1986.

Cane, H. V., Reames, D. V., and von Rosenvinge, T. T.: The role of interplanetary shocks in the longitude distribution of solar energetic particles, J. Geophys. Res., 93, 9555-9567, 1988.

Cliver, E. W., Kahler, S. W., and McIntosh, P. S.: Solar proton flares with weak impulsive phases, Astrophys. J., 264, 699-707, 1983.

Davis, T. N., and Sugiura, M.: Auroral electrojet activity index $A E$ and its universal time variations, J. Geophys. Res., 71, 785-801, 1966.

Dungey, J. W.: Interplanetary magnetic field and the auroral zones, Phys. Rev. Lett., 6, 47-48, 1961.

Feldstein, Y. I., Dremukhina, L. A., Levitin, A. E., Mall, U., Alexeev, I. I., and Kalegaev, V. V.: Energetics of the magnetosphere during the magnetic storm, J. Atmos. Sol. Terr. Phys., 65, 429446, 2003.

Forbush, S. E.: Three unusual cosmic-ray increases possibly due to charged particles from the Sun, Phys. Rev., 70, 771-772, 1946.

Gleisner, H. and J. Watermann: Solar energetic particle flux enhancement as an indicator of halo coronal mass ejection geoeffectiveness, Space Weather, 4, S06006, doi:10.1029/2006SW000220, 2006.

Gonzalez, W. D. mand Tsurutani, B. T.: Criteria of interplanetary parameters causing intense magnetic storms $\left(D_{s t}<-100 \mathrm{nT}\right)$, Planet. Space, Sci., 35, 1101-1109, 1987.

Gonzalez, W. D., Joselyn, J. A., Kamide. Y., Kroehl, H. W., Rostoker, G., Tsurutani, B. T., and Vasyliunas, V. M.: What is a geomagnetic storm?, J. Geophys. Res., 99, 5771-5792, 1994.

Gonzalez, W. D., Tsurutani, B. T., and Cla de Gonzalez, A. L.: Interplanetary origin of geomagnetic storms, Space Sci. Rev., 88, 529-562, 1999. 
Gonzalez, W. D., Gonzalez, A. L. C., Sobral, J. H. A., Dal Lago, A., Vieira, L. E.: Solar and interplanetary causes of very intense geomagnetic storms, J. Atmos. Sol. Terr. Phys., 63, 403-412, 2001.

Gosling, J. T., McComas, D. J., Phillips, J. L., and Bame, S. J.: Geomagnetic activity associated with Earth passage of interplanetary shock disturbances and coronal mass ejections, J. Geophys. Res., 96, 7831-7839, 1991.

Kahler, S. W., Cliver, E. W., Cane, H. V., McGuire, R. E., Stone, R. G., and Sheely, N. R.: Solar filament eruptions and energetic particle events, Astrophys. J., 302, 504-510, 1986.

Kahler, S. W.: Ann. Rev. Astron. Astrophys., 30, 113-141, 1992.

Lu, G., Baker, D. N., McPherron, R. L., et al.: Global energy deposition during the January 1997 magnetic cloud event, J. Geophys. Res., 103, 11 685-11 694, 1998.

Mason, G. M. and Sanderson T. R.: CIR associated energetic particles in the inner and middle heliosphere, Space Sci. Rev., 89, 77-90, 1999.

O'Brien, T. P. and McPherron, R. L.: An empirical phase space analysis of ring current dynamics: Solar wind control of injection and decay, J. Geophys. Res., 105, 7701-7719, 2000.

Reames, D. V.: Space Sci. Rev., 90, 413-491, 1999.

Russell, C. T., Lu, G., and Luhmann, J. G.: Lessons from the ring current injection during the September 24, 25, 1998 storm, Geophys. Res. Lett., 27, 1371-1374, 2000.

Shea, M. A. and Smart, D. F.: Relativistic solar proton events- evidence for a dual-stage injection scenario, Proc. 3rd. SOLar connection with Transient Interplanetary Phenomena Symposium, 467-474, 1998.

Singer, S. F.: A new model of magnetic storms and aurorae, Eos Trans. AGU, 38, 175-190, 1957.

Smith, Z., Murtagh, W., and Smithtro, C.: Relationship between solar wind low-energy energetic ion enhancements and large geomagnetic storms, J. Geophys. Res., 109, A01110, doi:10.1029/2003JA010044, 2004.

Sugiura, M. and Chapman, S.: The average morphology of geomagnetic storms with sudden commencement, Abh. Akad. Wiss. Göttingen, Math.-phys., Kl., Sonderheft, Spec. Issue 4, 3-53, 1960.
Sugiura, M.: Hourly values of equatorial $D_{s t}$ for IGY, Annals of the International Geophysical Year, Pergamon Press, Oxford, 35, 945-948, 1964.

Takalo, J. and Timonen, J.: On the relation of the $A E$ and $P C$ indices, J. Geophys. Res., 103, 29393-29398, 1998.

Troshichev, O. A., Dmitrieva, N. P., and Kuznetsov, B. M.: Polar cap magnetic activity as signature of substorm development, Planet. Space Sci., 27, 217-221, 1979.

Troshichev, O. A., Andrezen, V. G., Vennerstrm, S., and FriisChristensen, E.: Magnetic activity in the polar cap - A new index, Planet. Space Sci., 36, 1095-1102, 1988.

Troshichev, O. A. and Lukianova, R. Yu.: Relation of $P C$ index to the solar wind parameters and substorm activity in time of magnetic storms, J. Atmos. Sol. Terr. Phys., 64, 585-591, 2002.

Tsurutani, B. T. and Gonzalez, W. D.: The interplanetary causes of magnetic storms: A review, in Magnetic Storms, Geophys. Monogr. Ser., vol. 98, edited by: B. T. Tsurutani, W. D. Gonzalez, Y. Kamide and J. K. Arballo, 77-89, AGU, Washington, D. C., 1997

Vassiliadis, D., Angelopoulos, V., Baker, D. N., and Klimas, A. J.: The relation between the northern polar cap and auroral electrojet geomagnetic indices in the wintertime, Geophys. Res. Lett., 23, 2781-2784, 1996.

Vennerstroem, S. and Friis-Christensen, E.: Comparison between the polar cap, $P C$, and the auroral electrojet indicex $A E, \mathrm{AL}$ and AU, J. Geophys. Res., 96 (A1), 101-113, 1991.

Wang, C. L., Shen, C. L., Wang, S., and Ye, P. Z.: An empirical formula relating the geomagnetic storm's intensity to the interplanetary parameters: $-V B_{z}$ and $\Delta t$, Geophys. Res. Lett., 30, 2039-2042, 2003.

Zhang, M., Golub L., Deluca, E., and Burkepile, J.: The timing of flares associated with the two dynamical types of solar coronal mass ejections, Astrophys. J., 574, L97-L100, 2002. 